This item was submitted to Loughborough's Research Repository by the author.

Items in Figshare are protected by copyright, with all rights reserved, unless otherwise indicated.

\title{
More space, better mathematics: is space a powerful tool or a cornerstone for understanding arithmetic?
}

PLEASE CITE THE PUBLISHED VERSION

https://doi.org/10.1007/978-3-319-98767-5_4

\section{PUBLISHER}

Springer

VERSION

AM (Accepted Manuscript)

\section{PUBLISHER STATEMENT}

This book chapter was published in the book Visualizing Mathematics: The Role of Spatial Reasoning in Mathematical Thought [@ Springer Nature Switzerland AG]. The definitive published version is available at https://doi.org/10.1007/978-3-319-98767-5_4.

\section{LICENCE}

CC BY-NC-ND 4.0

\section{REPOSITORY RECORD}

Cipora, Krzysztof, Philipp Alexander Schroeder, Mojtaba Soltanlou, and Hans-Christoph Nuerk. 2018. "More Space, Better Mathematics: Is Space a Powerful Tool or a Cornerstone for Understanding Arithmetic?". Loughborough University. https://hdl.handle.net/2134/12210161.v1. 


\section{More Space, Better Mathematics:}

\section{Is Space a Powerful Tool or a Cornerstone for Understanding Arithmetic?}

Krzysztof Cipora1, Philipp Alexander Schroeder ${ }^{1,2}$, Mojtaba Soltanlou ${ }^{1,3}$, Hans-Christoph Nuerk $^{1,4,5}$

${ }^{1}$ Department of Psychology, University of Tuebingen, Germany

2 Department of Psychiatry and Psychotherapy, University of Tuebingen, Germany

${ }^{3}$ Graduate Training Centre of Neuroscience/ IMPRS for Cognitive and Systems Neuroscience, Germany

${ }^{4}$ Leibnitz-Institut für Wissensmedien, Germany

${ }^{5}$ LEAD Graduate School \& Research Network, Germany

Please send correspondence to Dr. K. Cipora (krzysztof.cipora@uni-tuebingen.de) or Prof. Dr. H.C. Nuerk (hc.nuerk@uni-tuebingen.de)

Cipora K., Schroeder P.A., Soltanlou M., \& Nuerk H.-C. (2018). More space, better mathematics: is space a powerful tool or a cornerstone for understanding arithmetic?. In: Mix K., Battista M. (eds) Visualizing Mathematics. Research in Mathematics Education (p. 77-116). Springer, Cham. https://doi.org/10.1007/978-3-319-98767-5_4

Version 3 of the preprint. Adjusted title and information on citation. 


\section{ABSTRACT}

Undoubtedly, tight links between space and number processing exist. Usually, findings of Spatial-Numerical Associations (SNA) are interpreted causally, i.e., that spatial capabilities aid or are even a fundamental cornerstone of mathematical skill. In this book chapter, we question this seemingly ubiquitous assumption.

To start with, there is no robust and prevalent correlation between SNA in general and math abilities. After presenting an extended taxonomy for different SNA subtypes, we show that only some SNA subtypes correlate with math abilities, whereas others do not. We argue that these correlations are not conclusive for several reasons. (i) Their correlations vary (i.e., stronger SNA sometimes is related to better math ability, and sometimes to poorer math ability). (ii) The correlations might not show a genuine relation between space and number; rather mediator variables might explain the correlations. For instance, SNA tasks often involve an interference component tapping cognitive control functions (as in multi-digit number processing) or some relatively advanced reasoning skills or strategies. (iii) Finally, the direction of causality (if it exists) is far from resolved. While conventional theories suggest that spatial-numerical abilities underlie arithmetic skill, we argue that vice versa arithmetic abilities instead underlie performance in some spatial-numerical tasks used to assess spatial-numerical representations.

On the other hand, benefits conferred by SNA trainings on math abilities seem to reinforce the claim that SNA underlies math abilities. We contend that tasks used in such trainings may tap several cognitive operations required in arithmetic, but not built-up fixed SNAs themselves. Therefore, we argue that using space is a powerful tool, especially for instructing and learning multi-digit numbers; however, this does not necessarily imply an internalized fixed mental number line. 


\section{Numbers and space - a long-lasting relationship}

The idea that numerical magnitudes could be represented on a directed mental line appeared very early in the history of mathematics. Dating back to the Greek philosophers of Aristotle's era, it was known that numerical magnitudes may be represented by a geometric line. In the Middle Ages, Campanus of Novara argued that a ratio found in one type of continuum can also be found in another. Subsequently, the medieval mathematician Nicole Oresme became a pioneer of quantifying space in terms of a multi-axis coordinate system (see Grant, 1972). That idea was later popularized and developed by René Descartes, after whom the widely-used perpendicular coordinate system was named.

The mathematical concept of the number line (and coordinate systems in particular) and the possibility to transfer abstract numerical quantities onto space substantially influenced the development of mathematics. Nevertheless, the mapping of numbers onto space (and quantifying space by means of numbers) is not a totally abstract or arbitrary invention. There is little doubt that spatial and numerical representations can be tightly and bidirectionally associated; there are numerous examples that this can happen both voluntarily and relatively automatically (e.g., Shaki \& Fischer, 2014). It was also demonstrated that non-numerical spatial abilities and math abilities are correlated (Mix et al., 2016), which may also indicate common underlying cognitive mechanisms.

In the present book chapter, we use the term Spatial-Numerical Associations (SNAs; see Cipora, Patro, \& Nuerk, 2015, for elaboration) to refer to a broad range of different behavioral phenomena (see Box 1). We shall see that there is no agreement about the origins of SNAs, i.e., whether they are innate or shaped by culture (including exposure to conventional representations of numbers on rulers, graphs and so on). Here, we argue that one possible reason for such disagreements is that SNAs consist of different phenomena, differing in their origins, their general characteristics and their propensity to be changed by situated influences. 
We also discuss how particular SNAs are related to school math achievement and outline that some SNAs are not predictive of later arithmetic performance, whereas others are fundamentally necessary. SNA trainings have been shown to transfer to other arithmetic skills; we will discuss why this may be the case, and in particular, whether a spatial-numerical representation per se is improved by training, or whether such training use space and its potential to be associated with number as a powerful tool to train other numerical skills and representations. For each SNA type, we discuss whether and how it informs math education with regard to trainings and other possibilities for intervention.

\section{Space and numbers live next to each other}

One of the first scientific inquiries on how humans represent numbers revealed that thinking of numbers includes some spatial components, at least in some people. In a paper published in 1880, Sir Francis Galton (Charles Darwin's cousin) described several reports of individuals who claimed to possess very vivid spatial visualizations of numbers (Galton, 1880). These usually took complex curvilinear forms, and according to the reports of people who experienced them, specific number representations remained precise and stable over time. Such explicit spatial number forms (i.e., directly available in self-reports) are pronounced in a considerable proportion of the general population (estimates vary from $2.2 \%$ to $29.0 \%$ of the population), and are referred to as synaesthetic visuo-spatial forms (e.g., Simner, Mayo, \& Spiller, 2009). Nevertheless, number-space synaesthetes (and their variable visualizations) are to some degree exceptional, and there has been a debate as to how far their spatial-numerical representations can inform us about the general population (e.g., Cohen Kadosh \& Henik, 2007).

Moyer and Landauer (1967) were the first to describe the numerical distance effect (see Box 1). This effect refers to the behavioral finding of shorter response times on a comparison task, when the numerical difference increases between the target stimulus (e.g., the numbers 1 or 4 ) 
and the referent number (e.g., 5, to which 1 or 4 are compared). The authors explained their finding with the claim that numerical magnitudes are converted to analogue magnitudes, which are then compared (and thus it takes longer to compare numbers that are closer together). While the distance effect has been interpreted in a spatial framework, the assumption of a spatial organization of number magnitude is not necessary to account for the effect. Following up on Moyer and Landauer's (1967) work, Restle (1970) developed the concept of the Mental Number Line (MNL) as an analog system, which organizes the representation of all numbers by distinctive markers placed on a visual line. Making numerical judgment requires the participants to "zoom in" on the MNL close enough so that numbers to be compared are located in different regions. Thus, the smaller the difference between numbers to be compared, the more "zooming in" operations need to be carried out. Restle's concept of the number line has seen differentiations and extensions. For instance it was suggested that multiple number lines are activated for multi-symbol numbers and not only one analog number line (Nuerk, Moeller, \& Willmes, 2015).

\section{SNA - not a single melting pot}

Space is not only related to number magnitude representation, but also to other mathematical representations (numerical intervals, ordinality, mathematic functions; see M. H. Fischer \& Shaki, 2014). However, it seems that the SNA term describes a relatively general property of cognition, which needs to be further specified. Although the vast majority of studies have been sound and conclusive, their results unfortunately cannot be combined easily to provide the big picture of how numbers are associated with space. Furthermore, the very general yet reasonable question of whether and to which extent SNAs are important for arithmetic (or even more broadly mathematics) learning is highly dependent on the type of SNA under study. Differences in SNAs will be elaborated on in detail in subsequent parts of the chapter. 


\section{Numbers and space: Fundamental principles and questions}

An overview of tasks used to measure SNAs is provided in Box 2. Tight relationships between space and number can be observed in varied tasks, age groups, and even species.

\section{Grounded, Embodied and Situated Influences on SNA}

One implicit assumption about SNAs is that they change during development, but are rather stable across different situations (i.e., similar to personality characteristics). However, an increasing amount of evidence converges to show that SNAs may also be subject to situated influences (see M. H. Fischer, 2012 for theoretical justification and introduction to this term; Wasner, Moeller, Fischer, \& Nuerk, 2014 for applications in other areas).

The common assumption regarding embodied (in a general sense) influences is that sensory and motor experiences present during the acquisition of knowledge (such as semantic number magnitude) are re-activated during retrieval and when operations are performed.

Within these general embodied influences, according to Fischer (2012), SNAs can be influenced by grounded, embodied, and situated influences, which we will briefly explain in the following section:

- Grounded principles are reflected in universal rules of number semantics such as the fact that larger numerosities imply physically "more" of something, including parts of smaller numerosities (M. H. Fischer, 2012), or the vertical association of larger numerosities with higher physical space (Wiemers, Bekkering, \& Lindemann, 2017).

- Embodied influences (in a narrower sense) refer to bodily influences and cultural sensorimotor experiences that influence cognition even though they might not be immediately relevant to a situation. For instance, the SNARC effect (see Box 1 ) is moderated by the reading direction of a language (e.g., Shaki, Fischer \& Petrusic, 2009). 
- Situated influences are nested in the empirical context or experimental situation: For instance, situated influences on SNAs are shown when the SNARC effect in bilinguals changes from one experimental situation in which words are presented in a left-to-right written language, to another experimental situation in which words are presented in a right-to-left written context (M. H. Fischer, Shaki, \& Cruise, 2009). In a similar vein, finger counting habits (generally considered a directional embodied influence) were remarkably different for participants that were simply told to either use their fingers for counting, to hold their hands in front of them to count aloud, or to indicate their counting habits themselves in a questionnaire (i.e., their hands were occupied; Wasner, Moeller, Fischer, \& Nuerk, 2014). The difference between embodied and situated influences is that embodied influences are culturally learnt and may not be induced by the experimental situation, but nevertheless modulate cognition between different cultural groups. Situated influences are specific to the particular experimental or empirical situation in which an effect or an underlying representation is assessed.

It is important to note that situated influences can be further distinguished (Cipora, Patro, \& Nuerk, in press). A more exhaustive overview and a taxonomy on situated influences on SNA is beyond the scope of this chapter.

Several empirical studies have tested grounded, embodied and situated modulations of the directional SNAs from brief interventions to long-term trainings, either to study their fundamental features and demonstrate their underlying mechanisms or to study potential interventions. In fact, several factors allow for re-training the shape of SNAs, yet the impact of these interventions or training on arithmetic is unclear. Notably, effects of embodied cultural differences due to reading direction have been established in different experimental studies (Moeller, Shaki, Göbel, \& Nuerk, 2015; Shaki, Fischer, \& Petrusic, 2009), which indicate that 
culturally experienced sensorimotor interactions with the environment, such as eye movements in reading a language, can shape SNAs.

\section{Correlations of SNA and arithmetic skill and potential underlying mechanisms}

The question of whether SNAs are related to arithmetic skill is in our view much too broad to be answered adequately, since it depends on which SNA is considered. Some studies report that stronger or more adequate SNAs are related to better math skills (e.g., Siegler \& Ramani, 2009). Other studies indicate no such effects (Cipora \& Nuerk, 2013), whereas a third category of studies show that stronger SNAs are related to poorer math skills (Hoffmann, Mussolin, Martin, \& Schiltz, 2014). With such varied results, it seems essential to consider different SNA types separately. Furthermore, mediating variables, such as domain general cognitive factors (Hohol, Cipora, Willmes, \& Nuerk, 2017) and knowledge of formal principles of math should be taken into account.

First of all, several SNA types can equally be considered compatibility effects (see Box 1). Like compatibility effects, the SNA indexes the extent to which irrelevant information influences processing of the currently relevant numerical or spatial information. In order to successfully perform the task, one in fact needs to refrain from processing the interfering information in half

of the trials. Therefore, domain-general processes (see Box 1) need to be involved to inhibit the irrelevant aspect of the stimuli/response, such as physical size, distance between numbers, or implicit mapping of numerical magnitudes onto space.

Some of these operations seem to be governed especially by executive functions, which themselves have been shown to correlate with math skill level (Cragg \& Gilmore, 2014; Nemati et al., in press) or with directional SNA (Hoffmann, Pigat, \& Schiltz, 2014). Thus, it seems that interference-based SNA should either not correlate or correlate negatively with math achievement. In fact, this view is supported by several studies (see Cipora et al. 2015 for review). 
Knowledge of formal rules of math may not only influence arithmetic skill directly, but also mediate the relationship between SNA and arithmetic skill. SNAs related to explicit counting direction in children can serve as an example: Through numerical development, it is very important that the child realizes and understands that the direction of counting elements is in fact irrelevant to the counting operation (Gelman \& Gallistel, 1978). Namely, this means that it does not matter where the sequence is started for counting. Thus, successful acquisition and use of numerical knowledge in fact require a cognitive flexibility that would undermine the SNAs related to a particular direction. Sometimes the formal knowledge counters SNA in ways that are even more specific. When solving calculation problems, the physical size of digits does not directly influence their meaning. On the other hand, in problems such as " $2^{5}+5^{2}=$ ?", differences in physical sizes carry arbitrary semantic information. Namely, the smaller size of the superscript does not mean that these numbers are either numerically smaller or less important, but instead provides information about the required operation. In that case, proper calculation requires (1) knowledge of the arbitrary rule on power notation and (2) inhibition of SNA, which would misleadingly associate smaller extension in the superscript with smaller number magnitude.

On the contrary, the potential correlation between performance in explicit number line estimation tasks (see Box 2) and arithmetic seems theoretically justified. The accurate mapping of numbers onto spatial locations requires an understanding of numerical magnitude and relations between numbers. In this case, the SNA is not reflected by the interference effect and does not go against formal math knowledge. On the other hand, such correlation is not very surprising because the very strategies that underlie good number line estimation rely on arithmetic skills (Barth, Starr, \& Sullivan, 2009; Link, Huber, Nuerk, \& Moeller, 2014; Link, Nuerk, \& Moeller, 2014). 
Even if correlations are observed, one still needs to be cautious in their interpretation. This is particularly the case in children's studies, because developmental changes can naturally produce changes in both arithmetic and NLE abilities separately. Especially in studying predictors of later arithmetic achievement, it is thus essential to include multiple measures and control variables in order to avoid flagging a correlation as meaningful, when it is actually driven by shared covariation due to age or another aspect of development. For example, improvements in two conceptually unrelated abilities such as the speed of running and math ability would both increase from grade 1 to grade 2 of schooling. Thus, if both measures were assessed at grade 1 and grade 2, a positive correlation would reflect shared variance due to age (being a mediating variable), but would not indicate that running speed could predict later achievements in mathematics. Of course, the same mediation of a correlation by another variable would be more critical to assess in potentially meaningful predictors of arithmetic achievement, such as counting abilities, working memory, or something else. Thus, a correlation is mediated if it is explained (partialled out) by another variable, which correlates with both variables of the original correlation.

To sum up, there is no general and consistent pattern of correlations between SNA and arithmetic skill, as some SNAs are consistently related to arithmetic skill (number line estimation) while others (SNARC) are not consistently related to arithmetic skill. In the following sections we present evidence for relationships (or lack thereof) between particular SNA types and arithmetic skill.

\section{Causal relations: What can be derived from training studies? Implications and caveats}

Apart from practical implications, the development of efficient trainings can also shed light on underlying theories and causal relationships as well. Namely, the fact that a given training is 
efficient provides evidence for a causal nature of relations between constructs of interest. However, some caveats apply.

Even if a training is successful, it often consists of several modules or representations. For instance, in spatial-numerical trainings, one might enhance spatial representations and processes, numerical representations and processes, or their relations. Even within numerical cognition, it might not be trivial to pinpoint the aspects that directly or indirectly relate to arithmetic abilities. What is more, additional variables such as gender or socioeconomic status may render trainings more effective in different learners. Thus, training programs may be tailored to a particular group: for instance, embodied trainings might be successful for typically developing children, but may not function for children with learning disabilities, because the instructions for the motor action in embodied training place too high a demand on working memory or other cognitive resources. Or vice versa, an embodied training might not further help typically developing children, but may facilitate learning in disabled children for whom normal instruction is not sufficient. In sum, causal implications from successful or unsuccessful trainings are not as straightforward as one might presume.

In this chapter, we focus on spatial-numerical trainings. However, we wish to make explicit that these are not the only successful numerical trainings. Training on other tasks, such as the MNL task or non-symbolic magnitude comparison, could also change mathematical performance either directly or indirectly by improving domain-general abilities.

By introducing the fundamental principles and questions in SNA research, we have now laid the groundwork for a new and extended taxonomy for SNAs.

$<$ Insert Box 2 here> 


\section{A new taxonomy for SNAs: How different SNAs have to be}

\section{differentiated}

Patro et al. (2014) outlined the first proposal of a systematic SNA taxonomy, which considered only phenomena that can be observed in preliterate children. Subsequently, Cipora et al. (2015) extended this taxonomy by including SNAs observed in adults. Here we partially clarify and extend it further by adding place-value processing as an instance of directional SNA considering both implicit and explicit coding components. The graphic summary of the taxonomy is presented in Figure 1.

\section{<insert Figure 1 here>}

The taxonomy will be discussed in the following paragraphs together with results demonstrating relationships (or a lack thereof) between particular SNA types and arithmetic skill. Furthermore, wherever such evidence exists, we will discuss situated influences on a given SNA type. In line with Cipora et al. (in press), we will classify manipulations of situated influences into categories depending on which stage of information processing was affected (perceptual, representational, action) and when the manipulation was applied (pre-experimental or intra-experimental). Note that this taxonomy does not consider the numerical distance effect or the size effect. Assuming the analog system of numerical magnitude does not necessarily imply existence of a spatial component. The MNL does not need to be spatially mapped / oriented in order to explain the numerical distance effect or the size effect (see Bonato, Fabbri, Umiltà, \& Zorzi, 2007; Cipora et al., 2015). These two fascinating phenomena fall outside the scope of the taxonomy. 


\section{Overview of the taxonomy}

The primary taxonomy proposal introduced by Patro et al. (2014) includes the distinction between extension SNA and directional SNA. Within extension SNA there are two subcategories: (a) approximate (formerly cardinality) and (b) exact (formerly interval). Cipora et al. (2015) further subdivided directional SNAs into two categories: (1) SNAs related to implicit coding of numerical magnitude, and (2) those related to explicit coding. Within each subcategory, Patro et al. (2014) differentiated SNA types related to cardinality and ordinality, and Cipora et al. (2015) added a third category of functions.

\section{Category Extension SNA: subcategory approximate}

\section{Type and paradigms}

This SNA type might be observed very early in development (e.g., de Hevia \& Spelke, 2011), in non-human animals (Tudusciuc \& Nieder, 2007) as well as in adults (Henik \& Tzelgov, 1982). For example, the size congruity effect is present when numerals of different physical sizes are shown, and responses are facilitated if semantic and physical size information are matched (Henik \& Tzelgov, 1982). A more exhaustive overview of experimental paradigms is presented in Box 2. Importantly, the relationship between space and numbers is bidirectional. Spatial aspects of the stimuli also affect numerical judgments (e.g., widely spaced numbers are judged to be more numerically distant; Lonnemann, Krinzinger, Knops, \& Willmes, 2008). Interference between space and numbers seems not to be restricted to simple numerical judgment, but also affects calculation efficiency. Facing problems like " $2 * 2+2$ " vs. " $2 * 2+2$ " (i.e., the problem is identical but spacing differs), participants are faster and more accurate in the first problem as the spatial arrangement corresponds to proper operation order (Landy \& Goldstone, 2010). We have previously called this category cardinality, but now term it approximate, because the above examples are not about exact relations between the physical and numerical space (like intervals in the number line estimation task described further on), but rather about larger magnitudes in 
one dimension being related to magnitudes or functions in another dimension, while the exact relationship is usually not important and unspecified.

Terming this subcategory approximate was also inspired by our proposal to take studies of the approximate number system (ANS, see Box 1) into this subcategory. ANS studies are not usually considered a SNA; however, based on more recent research, we postulate that approximate extension SNAs are in fact an important factor which needs to be considered when analyzing results of these studies (Dietrich, Huber, \& Nuerk, 2015; Gebuis \& Reynvoet, 2012). In ANS studies, non-symbolic sets are judged and spatial parameters such as extension, density, size, and others have been found to interfere with numerosity (see e.g. Leibovich \& Henik, 2013). Thus, visual properties of the stimuli presented in the typical ANS task are either positively or negatively correlated with the actual number of elements present within each set. This means that larger spatial extension (or another parameter) is either consistent with larger numerosity or interferes with it. If the association is consistent, performance is usually better (Szücs, Nobes, Devine, Gabriel, \& Gebuis, 2013).

\section{Situatedness}

Studies on situated influences on this SNA category are rather scarce. Usually, researchers were interested in demonstrating the phenomena and sometimes in looking for correlations between SNAs and other cognitive characteristics. One notable exception is the experiment by Fornaciai et al. (2016), which documented that numerosities of dot collections are systematically

underestimated when the dots are connected by task-irrelevant lines. This result is supported by different patterns of psychometric functions of numerosity that adapt depending on whether the lines are present or not in the display. Nevertheless, this field requires further exploration.

Correlations with arithmetic skill 
The relationship between approximate extension SNA and arithmetic skill has mostly been looked at with ANS studies. The general rationale is that an understanding of non-symbolic magnitude, e.g., of set sizes in visual dot patterns, would constitute the deep basis of any magnitude-related activities, including formal mathematics (Feigenson, Dehaene, \& Spelke, 2004). Despite these strong theoretical foundations, usually the observed correlations were either non-existent (e.g., Sasanguie \& Reynvoet, 2014), or very small, around $r=.2$, and decrease with age (Schneider et al., 2017 for meta-analysis).

Even these relatively low (but theoretically sound) correlations need to be treated with caution. As we mentioned above, when one has to compare two sets of dots, apart from numerosity they also differ by spatial features (Szücs et al., 2013). In so-called compatible trials, physical features (e.g., convex hull, overall area covered by the elements, size of elements) correlate with the number of elements. In so-called incompatible trials, the visual features correlate negatively with the number of elements. In this case, if the task is to judge numerosities, strong SNA would be beneficial for compatible trials but detrimental in incompatible trials. In some studies, the correlation between performance in non-symbolic comparison and arithmetic skill was not present any more when the interference component was controlled for (Cragg \& Gilmore, 2014). In fact, children seem to be often misguided by spatial components when solving numerical tasks (Stavy \& Tirosh, 2000) such that they tend to follow the principle "More A - More B". Despite being useful in everyday life (i.e., physical and temporal properties of objects are usually correlated with numbers, for instance a larger pile comprises more elements than a smaller one), formal mathematics requires abstracting from physical properties, e.g., despite having the same physical size, numbers refer to different magnitudes (Bueti \& Walsh, 2009).

Contemporary conceptions of the ANS include the multimodal processing of spatial and quantity information (Leibovich, Katzin, Harel, \& Henik, 2017), although it is important to highlight that 
one should always expect interactions between domain-general factors and a domain-specific factor such as the ANS (Hohol et al., 2017).

There are no genuine correlations between other instances of this SNA type and the arithmetic skill level as well. In particular, there were no correlations between the size congruity effect and math performance (Bugden \& Ansari, 2011; Rodic et al., 2015). Lonneman et al. (2008) observed that boys (8- to 9-year-olds) who exhibited stronger SNA in judging numerical and spatial distances performed math better. However, this effect was not present in girls. In general, it seems that this SNA category is not genuinely (or only weakly) correlated with arithmetic skill.

\section{Trainings}

Studies that use non-symbolic ANS tasks as training yield inconsistent results. Positive effects have been reported: for instance, two experiments on training in non-symbolic addition and subtraction improved performance in symbolic operations (Park \& Brannon, 2013). Another positive outcome was observed for children that engaged primitive quantities on exact arithmetic problems (Hyde, Khanum, \& Spelke, 2014). However, no such cross-over effect was observed in another large-scale study with children randomly assigned to different groups including training on exact numerosities (Obersteiner, Reiss, \& Ufer, 2013). Another recent study corroborated this negative result that extensive arithmetic training and substantial improvements in arithmetic performance were not reflected in matching ANS acuity changes (Lindskog, Winman, \& Poom, 2016). A possible indication of these inconsistent results would be to focus on the processes involved in mathematical operations and not only on the assumed numerical representation.

Category Extension SNA: Subcategory Exact

Type and paradigms 
Previously, we called this subcategory "Intervals". However, the difference between "approximate" and "exact" categories is the requirement of an exact (vs. approximate) match between spatial interval or a specific magnitude and the numerical interval of the magnitude. Performance is usually measured as a deviation from the exact match.

The number line estimation (NLE) task (see Box 2) involves associating number intervals with respective exact spatial extensions. The task itself is very easy to explain to the participants, including small children (e.g., 5- to 6-year-olds; Siegler \& Booth, 2004), which itself can be treated as an argument that mapping numerical magnitude onto spatial extensions is natural. This can be illustrated in a classical example where children always think that numerical magnitude maps onto spatial extension, and cannot detach from mapping extension to numerical quantity when distinct objects are presented; i.e., the Piagetian Number Conservation experiment (Gelman \& Gallistel, 1978). Performance in the NLE task has been linked to the internal representation of numerical magnitude (e.g., Siegler, 2009). It was claimed that with training, internal magnitude representation changes from a logarithmic format (i.e., large magnitude numbers are compressed) into a linear one (with equal distances between numbers). Nevertheless, the log-to-linear change in mental representation of the magnitude (Siegler \& Opfer, 2003) was challenged. It was shown that improvement of proportional judgment skill may explain the results better (i.e., typical bounded NLE is in fact solved by means of proportional judgment; Barth \& Paladino, 2011). The other challenging view was that performance in the task instead reflects place-value integration Moeller, Pixner, Zuber, Kaufmann, \& Nuerk, 2011), which will be discussed in subsequent parts of this chapter, or the ability to integrate familiar and unfamiliar numerical ranges (Ebersbach, Luwel, Frick, Onghena, \& Verschaffel, 2008). In general, these alternative explanations of non-linear response pattern in the NLE refer to some lack of thorough understanding of the numerical magnitude. 
To identify the processes underlying the NLE, another version of the task was developed - the unbounded NLE (Cohen \& Blanc-Goldhammer, 2011; see Box 2). This task variant was proposed to eliminate the proportional judgment component as well as more complex reasoning which also plays a role in case of bounded NLE (one might set up virtual anchor points in the middle of the line, then at quartile points, and adjust the exact estimation relative to these points e.g., to mark 77 one divides the line into halves and quarters and puts the estimation a little bit to the right of the virtual division point marking 75). Interestingly, the link between number line performance and arithmetic skill seems stronger for the bounded version of the task than for the unbounded one.

However, recently, Kim and Opfer (2017) argued that the log-to-linear change in the representation can provide a unifying framework for NLE. They used both bounded and unbounded NLE tasks. The mixed log-linear model (i.e., both components were included in one model) accounted for performance in both bounded and unbounded NLE. Performance in both tasks was strongly correlated $(r=.73)$. Interestingly, the overall performance accuracy was higher in bounded NLE compared to the supposedly easier (i.e., allowing summation strategy only) unbounded task. According to their interpretation, these results seem to support the log-tolinear shift. However, they are not in line with divergent validities, because the bounded number line correlates with arithmetic skill, while the unbounded number line does not (Link et al., 2014a,b). Link and colleagues (2014) suggested that bounded NLE allows the participants to use a wider range of available strategies. Undoubtedly, this issue is far from being resolved and we can expect intense discussion on the topic.

Finally, it is often observed in developmental studies that a linear correlation between numerical magnitude and space in the number line tasks takes different shapes in children, typical adults, and math-deficient adults. More precisely, children and math-deficient adults often assign larger inter-digit distances to magnitude steps in smaller ranges, which leads to a different shape of 
the correlation (Moeller et al., 2009). Often, it has been assumed that this behavior reflects a shift from logarithmically compressed number representations to a linear representation, mimicking one model fit for these patterns of results. However, it may be also possible that the behavior of children and math-deficient adults stems from a certain strategy for solving the task (Nuerk, Weger, \& Willmes, 2001). More precisely, the logarithmic pattern observed in the correlation (see Figures 1 and 2 in Moeller et al., 2009) can also be almost perfectly accounted for by two linear regressions, i.e., a bilinear fit for single- vs. multi-digit processing. In any case, proportional reasoning is always required, and thus we can infer that a benefit to other mathematical operations (that also often include proportional judgment) is also derived from this moderator variable. When solving the task and assigning space to numbers, such bilinear patterns would result from different strategies for mapping number magnitudes up to a certain point (e.g., 10) and then assigning the remaining space of the visually presented line to the remaining number magnitudes (e.g., up to 100). Educated adults that are asked to assign spatial distances on the number line task from 1 thousand to 1 billion (incorrectly) assign the half of the line to a landmark for 1 million (Landy, Silbert, \& Goldin, 2013), which reflects the bilinear strategy observed in children and points to a purely verbal (but not logarithmic compressed) strategy.

The representations underlying different task types of the NLE are still under heavy debate. Contradictory to many previous studies, Dietrich et al. (2016) argue that NLE might not be related to a spatial representation of numbers. The authors suggest that place-value understanding of the MNL task is most probably driven by the relationship between MNL and arithmetic performance (Booth \& Siegler, 2006). In line with this finding, a discontinuity of the MNL in very large numbers was reported, which was interpreted as reflecting a limitation of the magnitude perception system in humans (Landy, Charlesworth, \& Ottmar, 2014, 2017). All in all, although NLE is probably the task most frequently cited as providing evidence for the 
relationship between space and arithmetic, recent studies have started to cast doubt on this relationship and suggest some mediator processes between them.

\section{Situatedness}

Huber et al. (2014) demonstrated that providing feedback after each response may successfully train participants to perform the NLE task according to one of several models (linear, exponential, logarithm, sigmoid, inverted sigmoid). The training for each mapping consisted of only 30 trials. All participants participated in all conditions in counterbalanced order. Thus, it seemed as if that brief training successfully influenced NLE performance without changing the participants' numerical long-term representation (i.e., involving such a change for five times within one experimental session). Astonishingly, the follow up study detected a general deficit in adults with developmental dyscalculia (severe math impairments) with less precision in the NLE irrespective of the underlying shape (Huber, Sury, Moeller, Rubinsten, \& Nuerk, 2015).

Individuals with developmental dyscalculia had severe problems using benchmark points in this non-linear, but bounded NLE, again corroborating the idea that performance in the NLE is not only driven by spatial representation of number, but also by arithmetic strategies.

\section{Correlations with arithmetic skill}

The vast majority of studies on the relationship between this SNA type and arithmetic skill have reported zero order correlations (i.e., without an additional control variable partialled out). However, the overall picture gets much more complicated when one aims to investigate the nature of this relationship in a more detailed way. The extent to which linear function reflects a child's performance is correlated with his/ her math skill (see Siegler, Thompson, \& Opfer, 2009 for an overview). Lefevre et al. (2013) used a longitudinal experimental design to investigate the causality of these correlations. Their results showed that NLE performance could not predict future arithmetic performance better than arithmetic performance could predict future NLE 
performance. However, number system knowledge predicted future NLE performance. Thus, as the authors conclude, NLE is more related to math than to spatial performance.

Link et al. (2014) observed that only performance in the bounded NLE correlated significantly with arithmetic performance in fourth graders. This might suggest that fluency in making proportional judgments (i.e., relatively complex math reasoning) correlates with arithmetic performance. In other words, the results of the bounded NLE suggest that one type of math understanding correlates with another type of math understanding, which is in fact not very surprising. On the other hand, SNA itself (indexed with the unbounded task) seems not to be genuinely correlated with arithmetic performance.

In sum, we tend to agree with the conclusion of Dackermann et al. (2017) that the correlation between NLE and arithmetic skills may not mean that SNAs assessed by the NLE are (causally) important for arithmetic skills, but that vice versa, good arithmetic skills are causally important for good performance and application of helpful strategies in the NLE.

\section{Trainings}

Opfer and Siegler (2007) showed that presenting feedback rapidly and strongly improves NLE performance in second graders. Providing a single instance of feedback on accuracy in the task led to considerable improvements in performance (i.e., a log-to-linear change).

Potential beneficial effects of NLE tasks and training on numerical learning and arithmetic skill were obtained in respective studies. For instance, playing a board game designed to resemble the MNL for only $1 \mathrm{~h}$ improved the numerical understanding of low-income preschoolers (Siegler \& Ramani, 2009). More precisely, when children were assigned to play a linear board game as opposed to either a circular board game or a numerical control condition (including number counting, object counting, and number naming) - the researchers observed a steeper and more linear performance in the NLE task, more accurate performance in magnitude comparison 
tasks, and in addition problems. Additional experimentation showed the potential of extending the number board game to the 1-100 range, and that positive effects are distinct from those of control training with mere counting (Laski \& Siegler, 2014). The training is also effective in small group teaching setups (e.g., classroom context) and without extensive training of the teachers themselves (Ramani, Siegler, \& Hitti, 2012).

Throughout the last decade, several board games and computerized games targeting the link between number and space were developed and reported upon in different studies. Some aspects of instruction principles (e.g., adaptive increase of difficulty depending on recent performance) proved highly relevant to target the individual level of arithmetic skill, especially in computerized tasks (A. J. Wilson et al., 2006). In contrast, other aspects such as constructivism and intrinsic feedback are yet to be fully explored (Laurillard, 2016). Such interventions including the renowned scientific games Rescue Calcularis (Kucian et al., 2011), The Number Race, and The Number Catcher ${ }^{1}$ - are particularly thought to improve numerical skills in neurodevelopmental disorders such as dyscalculia (Kucian et al., 2011). Finally, finger-tracking technologies can be used to study number line mappings (e.g., Pinheiro-Chagas, Dotan, Piazza, \& Dehaene, 2017) or place-value structures (Bloechle, Huber, \& Moeller, 2015), which may allow for better targeting and investigation of the relevant cognitive processes underlying different number-space mappings.

Regarding evaluations, the most comprehensive evaluation of a single number training game to date was performed in a randomized controlled trial on the Number Race (Sella, Tressoldi, Lucangeli, \& Zorzi, 2016). In this trial, children were randomly assigned to play either the Number Race or an alternative computer-based activity, so that the comparison group was active in a different scope. Interestingly, Sella et al. (2016) observed large improvements in

${ }^{1}$ www.thenumberrace.com; http://www.thenumbercatcher.com/ 
mental calculation, number-space mappings, and smaller improvements in semantic processes, rendering an optimistic view on the training validity. In another study, when a more recent tablet version of the NLE game was contrasted with a comparison training in kindergarten children, both training methods elicited distinct and common learning effects (Maertens, De Smedt, Sasanguie, Elen, \& Reynvoet, 2016).

Accumulating evidence supports the broad theoretical notion that cognitive processes are embedded in corporeal experiences. This includes very basic interactions such as pointing and grasping objects and attributing numerical distance to spatial distance, as well as the use of finger counting. With accumulating sensory and motor interactions and learning transitions between these immediate physical experiences and the concepts of numerosity and magnitude, a rich and multimodal network evolves to allow for flexible representations and arithmetical procedures.

By implication, providing active opportunities for physical interactions could foster the development of abstract numerical or even arithmetic abilities. Some first evidence is available to support the embodied learning approach. For example, an intervention with first-graders included a NLE task with full-body involvement, i.e. walking to an estimated location displayed on the floor. Children showed more improvements with this intervention than a control group of children who solved the task without full-body involvement, not only in number line representations, but also in non-trained math-related tasks (Link, Moeller, Huber, Fischer, \& Nuerk, 2013). Furthermore, in kindergarten children, and compared to another numerical training without an active component, specific improvements were documented in embodied magnitude training (U. Fischer, Moeller, Bientzle, Cress, \& Nuerk, 2011). In this training study, full-body movements were incorporated for mathematical learning by use of a digital dance mat in magnitude classification tasks. The control group also performed magnitude comparisons in the training sessions with the same stimuli, but there was no presentation of a spatial number 
line and they solved the task on a tablet PC. Results showed enhanced mathematical performance following the active sensorimotor training mediated by mental number line representations. Such studies show the promising potential of vivid spatial-numerical activities for the acquisition of numerical concepts. Nevertheless, more research is required to particularly compare the novel training intervention to default procedures in large groups.

\section{Category: Directional SNA with implicit coding: Subcategory cardinalities}

\section{Type and paradigms}

In this SNA category the link between space and number is not highlighted in any instruction, and is not relevant to the task itself. Most often, space and numbers are highlighted separately in respective tasks, for instance, when magnitude classifications are indicated by left-hand vs. right-hand key presses.

The most important phenomenon that falls into this category is the SNARC effect (SpatialNumerical Associations of Response Codes; Dehaene et al., 1993; see Box 1) which refers to the faster speed of responses with the left hand than the right hand for small vs. large singledigit numbers.

Over past 24 years, the SNARC effect has been replicated numerous times and tested with varied participant groups (healthy individuals and clinical samples, of varied age), stimuli sets (both symbolic and non-symbolic), tasks (response criterion either referring or not referring to numerical magnitude), and response formats (see M. H. Fischer \& Shaki, 2014 for a current review; Wood, Willmes, Nuerk, \& Fischer, 2008 for a meta-analysis). Another SNA within this category is revealed by biases in random number generation (the participant is asked to generate random numbers) caused by either head (Loetscher, Schwarz, Schubiger, \& Brugger, 2008) or whole body movements (Schroeder \& Pfister, 2015; Shaki \& Fischer, 2014), and biases in numerical estimations caused by changes in body posture (Eerland, Guadalupe, \& 
Zwaan, 2011). Cultural influences such as reading habits in right-to-left reading Arabic countries can produce reverse effects (Shaki et al., 2009), although this was not observed in native speakers of Hebrew (but see Zohar-Shai, Tzelgov, Karni, \& Rubinsten, 2017).

\section{Situatedness}

Contextual cues that signal a different space-to-number assignment can modulate the SNARC effect (M. H. Fischer et al., 2010), but also previous episodes of responding with the incongruent mapping can instantly reduce regular SNAs in the next trial (Pfister et al., 2013). It is also possible to establish regular or reversed direction of SNARC effects by targeted training in children. For instance, children were asked to play a non-numerical spatial game on a touch screen, containing a frog that was moved across a pond either towards the left or right side of the screen (Patro et al., 2016). The direction of a SNARC effect depended on the direction of the training. This finding demonstrates that simple activities that are not necessarily related to numerical knowledge still impact associations between numbers and space. Conversely, this and related findings from situated numerical cognition, showing flexibility of SNAs in adults (e.g., Pfister et al., 2013), advise us to carefully gauge the value of exploring SNARC effects for arithmetic skill or as an effect of lifelong culturally dependent practice.

\section{Correlations with arithmetic skills}

Several positions exist in the contemporary literature concerning the relationship between SNARC and arithmetic skill in adults and children. It was suggested that adults skilled in math can be characterized by a weaker SNARC effect; however, the several results did not reach statistical significance (Dehaene et al., 1993, Exp. 1; Bonato et al., 2007; Bull et al., 2013; Cipora \& Nuerk, 2013). On the other hand, a relationship was found when individuals with math difficulties (Hoffmann et al., 2013) and professional mathematicians (Cipora et al., 2016) were considered. The SNARC effect seemed to decrease with increasing math proficiency. It 
suggests that differences in the SNARC effect get more pronounced in the case of extreme math skill groups but are either nonexistent or very weak at a typical math skill level.

The same seems to be true in the case of children (Gibson and Maurer, 2016) and adolescents (Schneider et al., 2009). On the other hand, Georges et al. (2017) reported a correlation. Interestingly, contrary to tendencies in adult studies, children who were characterized as having a stronger SNARC effect scored higher on a standardized math ability test. Bachot and colleagues (2005) observed that 7- to 12-year-olds with visuospatial disorder and developmental dyscalculia, contrary to a control group, do not reveal the SNARC effect. On the other hand, Crollen and Noël (2015) did not find such an effect in fourth graders with poor visuospatial abilities.

Together, these findings suggest that there is no consistent and genuine relationship between directional implicitly coded SNA for cardinalities and arithmetic or math, and the possible direction of the relationship is not consistent across development. However, one must take into account that across different studies math skill was operationalized in varied ways, ranging from performance in (speeded) calculation tests to categorical descriptions of individuals' field of study / occupation. This is important because of double dissociations between calculation proficiency and math expertise (Pesenti, 2005). According to Cipora et al. (2016), professional mathematicians who do not demonstrate the SNARC effect deal mostly with highly abstract constructs and for that reason their SNAs may be either non-existent or highly flexible.

To the best of our knowledge, there have been no studies investigating the relationship between math skill and other forms of this SNA subcategory. In our view, this should also be pursued in future studies.

\section{Trainings}


To the best of our knowledge there have been no training studies aimed at using this SNA type in order to improve math skills.

\section{Category: Directional SNA with implicit coding: Subcategory - ordinalities}

Type and paradigms

Directional SNAs can emerge due to the quantity present in numerical cardinality as well as due to the ordinal structure in numerical and non-numerical stimuli (such as series of objects, or sequentially arranged structures such as weekdays). Thus, with number symbols in the SNARC effect described above, it is ambiguous whether cardinal or ordinal information becomes spatially arranged. Complementing the influence of reading habits in left-to-right and right-to-left directed Western (English) and Eastern (Hebrew) languages, researchers tested these interrelations by means of ambiguous symbols that depict both ordinal series and quantity. For different tasks, either type of information was considered relevant, but interestingly, only the SNARC effect based on ordinality was found to follow participants' right-to-left reading direction. When the task emphasized the symbols' cardinality, a regular left-to-right direction was observed in the Hebrew-speaking participants (Shaki \& Gevers, 2011). In recent experiments, this apparent dissociation of spatial associations that are based on number and order was further investigated in Western culture. First, it was observed that the correlation between different SNARC effects was remarkably low for different cardinal (1-5) and ordinal stimuli (Monday-Friday sequence; Schroeder, Nuerk, \& Plewnia, in press) but also for the same numerical stimuli in different magnitude and parity classification tasks (Georges, Hoffmann, \& Schiltz, in press). Finally, spatial associations of ordinal and cardinal nature were clearly dissociated with transcranial brain stimulation (Schroeder, Nuerk, \& Plewnia, 2017). Thus, it is important to differentiate ordinal and cardinal aspects of SNAs also with respect to other behavioral and neurocognitive studies (Huber, Klein, Moeller, \& Willmes, 2016) and multiple cognitive processes seem to underlie the emergence of spatial associations (Schroeder, Nuerk, 
\& Plewnia, 2017). Nevertheless, the current data converge in that ordinal SNAs represent a separable and distinct directional SNA category.

\section{Situatedness}

In principle, it is plausible that situated influences can shape the direction and intensities of SNAs based on ordinality and cardinality alike. Memorizing a sequence of elements (i.e., ordinality information) evokes SNARC-like effects. When the participants were instructed to memorize randomized sequences of numbers (e.g., 9,2,5,6,3) and then performed parity judgments to classify these numbers, the SNARC effect reflected the order of numbers in a sequence, not their magnitudes (van Dijck \& Fias, 2011). Namely, elements from the beginning of the list were associated with the left hand side and those from the end, with the right hand side. Thus, it seemed that situated influence (memorizing a sequence carrying ordinal information) may cover up the (long-term or short-term) SNA related to cardinality of numbers constituting the sequence. Nevertheless, subsequent studies showed that in the case of number sequences, the SNARC effect can depend on both number magnitude and a position in a sequence (Huber, Klein, et al., 2016).

\section{Correlations with arithmetic skill}

So far, there no studies have demonstrated correlations of this SNA type with arithmetic skill. Nevertheless, it could be explored whether serial order working memory and ordinality deficits constitute different types of math deficit (e.g., Rubinsten \& Sury, 2011). Focusing on this area could help disambiguate between contradictory findings on the relationship between cardinal SNA and arithmetic skill, as in most cases both ordinal and cardinal properties of numbers are tightly connected.

\section{Trainings}


To the best of our knowledge there have been no training studies aimed at using this SNA type in order to improve math skills.

\section{Category: Directional SNA with implicit coding: Subcategory operations}

Type and paradigms

Not only basic numerical concepts are associated with space: so are arithmetic operations such as addition and subtraction. Even single "-“ and "+" signs are related to the left and right sides (operation sign spatial association - OSSA; Pinhas, Shaki, \& Fischer, 2014), but the spatial association also holds for entire arithmetic operations (see Box 1). This was described at different levels such as movements along the number line (Pinhas \& Fischer, 2008), eye movements (Klein, Huber, Nuerk, \& Moeller, 2014; Masson, Letesson, \& Pesenti, in press), attentional shifts (Masson \& Pesenti, 2014), and arm movements (Wiemers, Bekkering, \& Lindemann, 2014). This collection of phenomena is referred to as Operational Momentum. However, this term initially referred only to over- / under-estimation of the results of addition, multiplication / subtraction, division (McCrink, Dehaene, \& Dehaene-Lambertz, 2007).

\section{Situatedness}

To date, studies on spatial biases in mental arithmetic focused on demonstrating its various forms depending on modality (symbolic vs. non-symbolic) and type of spatial bias. To the best of our knowledge there have been no studies demonstrating situated influences on this effect.

Correlations with arithmetic skill

We are also not aware of studies demonstrating a relationship between spatial associations with arithmetic functions/operations and arithmetic skill level.

\section{Trainings}


To the best of our knowledge, there have been no specific training studies taking advantage of SNA related to implicit coding of arithmetic operations.

Category Directional SNA with explicit coding: Subcategory - ordinalities Type and paradigms

This SNA set refers to biases evoked explicitly by the task instruction. In tasks measuring this SNA type, participants are asked to count objects from a predetermined set. The direction is the dependent measure. Objects may be arranged linearly (either in a horizontal or vertical line) thus providing only two possibilities (e.g., Shaki, Fischer, \& Göbel, 2012) or objects may form an array providing more possibilities (e.g., Göbel, 2015). A special case pertains to finger counting (Lindemann, Alipour, \& Fischer, 2011).

In several instances such studies demonstrated that the counting direction was influenced by reading habits in a given culture. Moreover, culture-driven preference patterns become more pronounced during reading acquisition (Shaki et al., 2012). In general, in Western cultures both children and adults prefer counting from left to right. Individuals who use right-to-left script (e.g., Arab speakers) count from right to left. This suggests that both explicit and implicit SNAs are culturally modulated and subject to embodied moderations.

\section{Situatedness}

This SNA type is very prone to situated influences. In Cantonese (a Chinese language), speakers can use either vertical or horizontal script. Reading a short paragraph written vertically may affect Cantonese participants' counting directions (Göbel, 2015). Moreover, remarkably different proportions of right-starters (i.e., participants starting the finger counting sequence from their right hand) vs. left-starters emerged depending on whether participants were (a) asked to spontaneously count, (b) presented with a schematic drawing of hands, or (c) asked when their 
dominant hand was occupied (Wasner et al., 2014). All these results suggest that there is huge space for situated influences in this SNA category (at least for finger counting).

Correlations with arithmetic skill

To the best of our knowledge, there is no data showing correlations between this SNA type and arithmetic skill. Studies showing a relationship between finger gnosis and arithmetic skill in children (e.g., Penner-Wilger \& Anderson, 2013) are not instructive on this issue because they only demonstrate that an adequate representation of fingers seems to be related to arithmetic performance.

\section{Trainings}

Interventions indirectly related to this SNA type are hard to find. Of course, some finger counting interventions were related to finger gnosis, counting or cardinality (Gracia-Bafalluy \& Noël, 2008, but see J. P. Fischer, 2010 for a methodological critique). Improvement of finger gnosis or finger cardinality or finger counting was related to improvements in arithmetic skill. However, since these interventions were not aiming at SNAs, nor was the spatially organized finger counting routine exclusively trained, they cannot be considered directly related to SNAs.

Category Directional SNA and explicit coding: Subcategory cardinalities and operations The taxonomy proposed by Cipora et al. (2015) postulated the existence of those two SNA types, but nevertheless, they have not been reported in empirical studies so far.

\section{SNA with multi-digit numbers}

For operations on symbolic numbers, it may be intuitive to simply extend the concept of SNA. However, as we show in the following section, additional processes need to be considered. These processes may include parallel computation or even show distinct effects of integrating the values and their perceptual positions in place-value processing (Nuerk, Moeller, Klein, Willmes \& Fischer, 2011). Usually, multi-symbol number processing is not seen as a SNA. 
However, in the Arabic place-value processing, in fact it is one by many definitions. Therefore, we will discuss multi-symbol number processing in the remainder of this chapter from the SNA perspective.

\section{Multi-symbol processing as an integration of space and}

\section{magnitude}

The ability to understand multi-digit numbers such as 83,5729 , and 1000000 involves understanding the digits and the values imposed by their spatial positions. However, numbers are not only comprised of different digits, but also of other symbols like the "-" sign for negative number, the "." for decimal numbers, or the "l" or "_ " for fractions (Huber, Nuerk, Willmes, \& Moeller, 2016). Because we also refer to such numbers, which are comprised of digits and other symbols in certain spatial positions, we refer to multi-symbol numbers. It is important to note that not only the spatial positions of digits (29 vs. 92), but also the spatial positions of symbols (e.g., 2.93 vs. 29.3) change the value of the multi-symbol number. While this may appear obvious at first to educated adults, the perceptual and cognitive consequences of these highly overlearned characteristics can be even more informative regarding multi-digit processing. In the following, we will explain the relationship between the spatial and multi-symbol processing and domain-specific factors as a part of mathematics.

\section{Place-value system}

Multi-digit Arabic numbers rely on both value (number magnitude), e.g., 9 is larger than 4, and place (unit, decade, hundred, etc.), e.g., 4 as a decade is larger than 9 as a unit. Therefore, in order to process multi-digit numbers, one needs to integrate the value and the place (see Nuerk et al., 2015).

The place-value system simplifies calculation and allows fast, automatic calculation using typical algorithms. Based on the place-value system, Nuerk and colleagues (2015) suggested a new 
theoretical framework for multi-digit number processing, which comprises three distinctions: place identification, place-value activation, and place-value computation (cf. Box 1). In the following, we will discuss these three steps along with language influence, which is essential in multi-digit number processing.

\section{Place identification}

The first perceptual step in multi-digit number processing is to correctly identify the position of digits and symbols. As mentioned above, digits are arranged in a specific manner in multi-digit Arabic numbers, which leads to a differentiation between the two magnitudes in different places (unit, decade, hundred, etc.). Therefore, this processing level does not include semantic processing of the digits. However, language properties facilitate or interfere with place identification (Nuerk et al., 2015, for overview). For instance, Miura et al. (1994) observed that Japanese, Chinese, and Korean children, perform better in distinguishing units and decades compared to their counterparts from Western countries, i.e., the US, Sweden, and France. This difference is because Asian children learn Arabic multi-digit numbers based on a transparent number-word system (e.g., 38 is three ten eight), in contrast to Western children. Furthermore, interference between the place identification and the syntactic structure of number-words across languages may worsen performance (Nuerk et al., 2005). For example, in the German language, decade and unit digits are stated inversely (38 is read or said as "eight and thirty"), which leads to transcoding errors in half of the German-speaking 7-year-olds (Zuber, Pixner, Moeller, \& Nuerk, 2009). This might be even more pronounced in three-digit numbers, which are read in the order of hundreds (left digit), units (right digit) and then decades (middle digit). This observation exemplifies how verbal representation, as a linguistic feature, influences place identification.

\section{Place-value activation}


In the next step of multi-digit number processing, the integration of places and magnitudes of the digits is highlighted. For instance, in order to successfully compare two-digit numbers, individuals need to know to first compare the decades, which requires processing of both place and value (Nuerk et al., 2001). The unit-decade compatibility effect (cf. Box 1) in symbolic multidigit number comparison is an index of place-value activation. In unit-decade compatible pairs (e.g., 21_89) in a symbolic number comparison task, the unit comparison leads to the same response as the decade comparison. However, in unit-decade incompatible pairs (e.g., 29_93), the unit comparison leads to an error. Therefore, the place-value system has a critical influence on incompatible trials. Depending on the unit-decade compatibility, the place-value activation might have a more or less important influence on performance (Miura et al., 1994). It is important to note that the unit magnitude does not have to be processed when two two-digit numbers are to be compared. However, the compatibility effect automatically interferes with processing a digit when its identity and magnitude are irrelevant for the comparison in question.

Linguistic features such as inversion also influence the unit-decade compatibility effect, which leads to a more pronounced effect for instance in German speakers. Pixner and colleagues (2009) observed that the interference effect of unit magnitude is larger in German-speaking children compared to Italian-speaking children.

Furthermore, the interaction of the unit-decade compatibility effect with decade distance and unit distance requires place-value activation as well (Nuerk et al., 2001). What is important is that the distance effect (cf. Box 1) for two-digit numbers may be a better diagnostic marker than the distance effect for single-digit numbers. For instance, Ashkenazi, Mark-Zigdon \& Henik (2009) observed that dyscalculic children differed from controls in two-digit distance effects, but not in the single-digit distance effect. A possible reason is that single-digit numbers are highly overlearned, so that their processing does not differentiate between groups at different skill levels. Another explanation is that compared to single-digit numbers, multi-digit numbers involve 
SNAs and automatic place-value activation, which differ between dyscalculics and controls. However, while some studies have observed that number magnitude, i.e., a larger decade distance effect, negatively correlated with arithmetic performance (e.g., De Smedt, Verschaffel, \& Ghesquière, 2009), other studies documented a paradoxical positive relationship between the numerical distance effect and arithmetic performance (e.g., Moeller et al., 2011).

While most of the studies regarding three levels of place-value system involve explicit coding for instance, all of the above-mentioned studies - very few studies have investigated implicit place-value activation. In the study by Kallai and Tzelgov (2012), while participants were explicitly asked to compare only the value of two numbers including several zeros (e.g., 050 vs. 007), the place-value activation was documented. In another study, Ganor-Stern, Tzelgov, and Ellenbogen (2007) observed that the place-value activation interacts with the size congruency effect, while participants were not explicitly asked to decide about both place and value. The size congruency effect is related to processing of the (irrelevant) magnitude dimension when the task is to compare the (relevant) physical dimension of the decades. They suggested that the compatibility effect is automatic as it interacts with the size congruency effect.

\section{Place-value computation}

Place-value computation is one step further beyond place identification and place-value activation in multi-digit number processing. It refers to a manipulation of place-values, such as in carry operations. For instance, to solve $28+65$, the added magnitude of the units needs to be carried over to the decades $(80+13)$. Hence, the magnitudes of the units and decades in relation to each other and to their places need to be taken into account. Surprisingly, language has an influence on this higher level of place-value computation as well. Göbel and colleagues (2014) investigated addition problems with and without carry operations in German-speaking and Italian-speaking children. They reported a larger carry effect in the language with inversion (German) than without (Italian). As might be expected, because the added magnitude of the 
units needs to be kept in working memory, working memory mediated the carry effect. Complementary to these findings, Colome and colleagues (2010) reported the role of full base20 in the Basque number word system. Basque participants responded faster to the addition problems containing 20 and a teen number (e.g., 37 is said " $20+17$ ") rather than any other addition problems with similar results but other summands than 20 . Altogether, we conclude that understanding different levels of the place-value system is essential for multi-digit number processing and therefore, for numerical and arithmetic development.

\section{Training multi-digit numbers and predicting future performance}

Multi-digit number processing is a special case regarding trainings, because in contrast to other SNAs, its understanding is an explicit goal in education. As one of the basic numerical competencies, the place-value system develops during childhood and is clearly related to math achievement. In a longitudinal study, Moeller et al. (2011) observed that place-value understanding in first grade was a reliable predictor of arithmetic performance in third grade and suggested that it should be understood as a developmental process. Ho and Cheng (1997) observed that place-value training improved arithmetic performance in first graders. Altogether, place-value processing, which is the spatial arrangement of the digits in multi-digit numbers that leads to different evaluation of a digit in different places, helps us to learn and apply mathematical knowledge in multi-digit numbers in a less effortful way.

\section{Conclusions}

The leading question of this chapter was: is space a cornerstone or a powerful tool for learning and for understanding arithmetic? As often in science, there is no simple unitary answer on this question. First, there is not "THE" spatial-numerical association, but there are multiple SNAs, which differ in their spatial dimensions (e.g., extension, directionality) and their numerical dimensions (cardinality, ordinality, operations, place-value integration etc.). For some of them, 
stable correlations with arithmetic skill have been reported (e.g., extension, interval-scaled like in the NLE, place-value processing), while for others correlations are low, scarce and inconsistent (e.g., SNARC effect). Although exceptions apply, a general rule of thumb seems to be that SNAs related to the directionality in space (e.g., small numbers left, large numbers right) are usually not important for arithmetic skill.

However, when it comes to specific SNAs related to exact extension or (place-value) position, the picture is different. For both extension and positions, we see relatively stable correlations with arithmetic skill and indications that training these processes and representations successfully transfers to other arithmetic skills. It is unclear whether the spatial-numerical representation of numbers per se is trained (e.g., linear or logarithmic) or whether spatialnumerical tasks are a powerful tool to train associated number representations like magnitude representations or the internal power system underlying our base-10 place-value notation in Arabic numbers.

Here, we want to add a disclaimer in order not to be misunderstood. In our view, it is absolutely essential to have a functioning magnitude representation and a functioning representation of the base-10-system. There is no doubt that these systems can be mapped to space and that participants skillful in mathematics can use space as a powerful tool to facilitate their performance. Furthermore, there is convincing evidence that spatial visualizations are a powerful tool to train more complex internal mathematical representations. All these points are essentially undisputed. The reasons and the causality for these findings, however, are disputed. We still question whether a particular spatial-numerical representation is trained, which underlies all our mathematical understanding, or whether a spatial mapping can enhance our numerical representations and skills.

Our point can be illustrated by comparing spatial-numerical mappings to mnemonic techniques and methods in memory research. There is no question that they work, or that people who 
perform well in memory tasks can usually use them; there are training studies showing that they can improve memory performance. But does this mean that mnemonic representations underlie our memory system? Of course, every analogy has its limitations, but here we illustrate the general point that correlations and successful trainings do not automatically indicate an underlying representation. This is an open question for us.

Nevertheless, there is no doubt that space is at least an extremely powerful tool for learning and understanding arithmetic and probably the most important association with numbers and arithmetic besides language. We believe that it is impossible to fully understand arithmetic without understanding its relation to space in learning and operating numerical skills. So, although we believe that the case of particular underlying spatial representations is not as straightforward as it is sometimes assumed in the literature, we are convinced that SNAs deserve much more thorough and in-depth research in the future. However, in our view, the direction should be to understand the nature and impact of each different SNA rather than to demonstrate yet another SNA without particular reference to its function and impact.

\section{References}

Bachot, J., Gevers, W., Fias, W., \& Roeyers, H. (2005). Number sense in children with visuospatial disabilities : orientation of the mental number line. Psychology, 47(1), 172183.

Barth, H. C., \& Paladino, A. M. (2011). The development of numerical estimation: Evidence against a representational shift. Developmental Science, 14(1), 125-135. http://doi.org/10.1111/j.1467-7687.2010.00962.x

Barth, H. C., Starr, A., \& Sullivan, J. (2009). Children's mappings of large number words to 
numerosities. Cognitive Development, 24(3), 248-264.

http://doi.org/10.1016/j.cogdev.2009.04.001

Bloechle, J., Huber, S., \& Moeller, K. (2015). In touch with numbers: Embodied and situated effects in number magnitude comparison. Journal of Cognitive Psychology, 27(4), 478489. http://doi.org/10.1080/20445911.2014.1001760

Bonato, M., Fabbri, S., Umiltà, C., \& Zorzi, M. (2007). The mental representation of numerical fractions: Real or integer? Journal of Experimental Psychology: Human Perception and Performance, 33(6), 1410-1419. http://doi.org/10.1037/0096-1523.33.6.1410

Booth, J. L., \& Siegler, R. S. (2006). Developmental and individual differences in pure numerical estimation. Developmental Psychology, 41(6), 189-201. http://doi.org/10.1371/journal.pone.0165243

Brysbaert, M. (1995). Arabic number reading: On the nature of the numerical scale and the origin of phonological recoding. Journal of Experimental Psychology: General, 124(4), 434452. http://doi.org/10.1037/0096-3445.124.4.434

Bueti, D., \& Walsh, V. (2009). The parietal cortex and the representation of time, space, number and other magnitudes. Philosophical Transactions of the Royal Society of London. Series B, Biological Sciences, 364(1525), 1831-40. http://doi.org/10.1098/rstb.2009.0028

Bugden, S., \& Ansari, D. (2011). Individual differences in children's mathematical competence are related to the intentional but not automatic processing of Arabic numerals. Cognition, 118(1), 32-44. http://doi.org/10.1016/j.cognition.2010.09.005

Bull, R., Cleland, A. A., \& Mitchell, T. (2013). Sex differences in the spatial representation of number. Journal of Experimental Psychology. General, 142(1), 181-92. http://doi.org/10.1037/a0028387 
Cipora, K., Hohol, M., Nuerk, H.-C., Willmes, K., Brożek, B., Kucharzyk, B., \& Nęcka, E. (2016). Professional mathematicians differ from controls in their spatial-numerical associations. Psychological Research, 80(4), 710-26. http://doi.org/10.1007/s00426-015-0677-6

Cipora, K., \& Nuerk, H.-C. (2013). Is the SNARC effect related to the level of mathematics? No systematic relationship observed despite more power, more repetitions, and more direct assessment of arithmetic skill. Quarterly Journal of Experimental Psychology, 66(10), 1974-91. http://doi.org/10.1080/17470218.2013.772215

Cipora, K., Patro, K., \& Nuerk, H.-C. (in press). Situated influences on spatial-numerical associations. In T. Hubbard (Ed.), Spatial Biases in Perception and Cognition. Cambridge, UK: Cambridge University Press.

Cipora, K., Patro, K., \& Nuerk, H.-C. (2015). Are Spatial-Numerical Associations a Cornerstone for Arithmetic Learning ? The Lack of Genuine Correlations suggests: No. Mind, Brain, \& Education, 9(4), 190-207. http://doi.org/10.1111/mbe.12093

Cohen, D. J., \& Blanc-Goldhammer, D. (2011). Numerical bias in bounded and unbounded number line tasks. Psychonomic Bulletin \& Review, 18(2), 331-338. http://doi.org/10.3758/s13423-011-0059-z

Cohen Kadosh, R., \& Henik, A. (2007). Can synaesthesia research inform cognitive science? Trends in Cognitive Sciences, 11(4), 177-184. http://doi.org/10.1016/j.tics.2007.01.003

Cohen Kadosh, R., Lammertyn, J., \& Izard, V. (2008). Are numbers special? An overview of chronometric, neuroimaging, developmental and comparative studies of magnitude representation. Progress in Neurobiology, 84(2), 132-47. http://doi.org/10.1016/j.pneurobio.2007.11.001

Colome, A., Laka, I., \& Sebastian-Galles, N. (2010). Language effects in addition: How you say 
it counts. Quarterly Journal of Experimental Psychology, 63(5), 965-983.

http://doi.org/10.1080/17470210903134377

Cragg, L., \& Gilmore, C. (2014). Skills underlying mathematics: The role of executive function in the development of mathematics proficiency. Trends in Neuroscience and Education, 3(2), 63-68. http://doi.org/10.1016/j.tine.2013.12.001

Crollen, V., \& Noël, M. P. (2015). Spatial and numerical processing in children with high and low visuospatial abilities. Journal of Experimental Child Psychology, 132, 84-98. http://doi.org/10.1016/j.jecp.2014.12.006

Crollen, V., Vanderclausen, C., Allaire, F., Pollaris, A., \& No??I, M. P. (2015). Spatial and numerical processing in children with non-verbal learning disabilities. Research in Developmental Disabilities, 47, 61-72. http://doi.org/10.1016/j.ridd.2015.08.013

Dackermann, T., Fischer, U., Nuerk, H., \& Cress, U. (2017). Applying embodied cognition: From useful interventions and their theoretical underpinnings to practical applications. ZDM, 49(4), 545-557. http://doi.org/10.1007/s11858-017-0850-z

de Hevia, M. D., \& Spelke, E. S. (2011). Number-Space Mapping in Human Infants. Psychological Science, 21(5), 653-660. http://doi.org/10.1177/0956797610366091.

De Smedt, B., Verschaffel, L., \& Ghesquière, P. (2009). The predictive value of numerical magnitude comparison for individual differences in mathematics achievement. Journal of Experimental Child Psychology, 103(4), 469-479. http://doi.org/10.1016/j.jecp.2009.01.010

Dehaene, S., Bossini, S., \& Giraux, P. (1993). The mental representation of parity and number magnitude. Journal of Experimental Psychology: General, 122(3), 371-396. http://doi.org/10.1037/0096-3445.122.3.371

Dietrich, J. F., Huber, S., Dackermann, T., Moeller, K., \& Fischer, U. (2016). Place-value 
understanding in number line estimation predicts future arithmetic performance. British Journal of Developmental Psychology, 34(4), 502-517. http://doi.org/10.1111/bjdp.12146

Dietrich, J. F., Huber, S., \& Nuerk, H. C. (2015). Methodological aspects to be considered when measuring the approximate number system (ANS) - a research review. Frontiers in Psychology, 6, 295. http://doi.org/10.3389/fpsyg.2015.00295

Ebersbach, M., Luwel, K., Frick, A., Onghena, P., \& Verschaffel, L. (2008). The relationship between the shape of the mental number line and familiarity with numbers in 5- to 9-year old children: Evidence for a segmented linear model. Journal of Experimental Child Psychology, 99(1), 1-17. http://doi.org/10.1016/j.jecp.2007.08.006

Eerland, A., Guadalupe, T. M., \& Zwaan, R. A. (2011). Leaning to the left makes the Eiffel Tower seem smaller: posture-modulated estimation. Psychological Science, 22(12), 15114. http://doi.org/10.1177/0956797611420731

Feigenson, L., Dehaene, S., \& Spelke, E. (2004). Core systems of number. Trends in Cognitive Sciences, 8(7), 307-314. http://doi.org/10.1016/j.tics.2004.05.002

Fias, W., Lauwereyns, J., \& Lammertyn, J. (2001). Irrelevant digits affect feature-based attention depending on the overlap of neural circuits. Cognitive Brain Research, 12(3), 415-423. http://doi.org/10.1016/S0926-6410(01)00078-7

Fischer, J. P. (2010). Numerical performance increased by finger training: A fallacy due to regression toward the mean? Cortex, 46(2), 272-273.

http://doi.org/10.1016/j.cortex.2008.06.010

Fischer, M. H. (2001). Number processing induces spatial performance biases. Neurology, 57(5), 822-826. http://doi.org/10.1212/WNL.57.5.822

Fischer, M. H. (2012). A hierarchical view of grounded, embodied, and situated numerical 
cognition. Cognitive Processing, 13(Suppl 1), S161-S164. http://doi.org/10.1007/s10339012-0477-5

Fischer, M. H., Mills, R. A., \& Shaki, S. (2010). How to cook a SNARC: number placement in text rapidly changes spatial-numerical associations. Brain and Cognition, 72(3), 333-6. http://doi.org/10.1016/j.bandc.2009.10.010

Fischer, M. H., \& Shaki, S. (2014). Spatial associations in numerical cognition - From single digits to arithmetic. Quarterly Journal of Experimental Psychology, 67(8), 1461-1483. http://doi.org/10.1080/17470218.2014.927515

Fischer, M. H., Shaki, S., \& Cruise, A. (2009). It takes just one word to quash a SNARC. Experimental Psychology, 56(5), 361-6. http://doi.org/10.1027/1618-3169.56.5.361

Fischer, U., Moeller, K., Bientzle, M., Cress, U., \& Nuerk, H.-C. (2011). Sensori-motor spatial training of number magnitude representation. Psychonomic Bulletin \& Review, 18(1), 177183. http://doi.org/10.3758/s13423-010-0031-3

Fornaciai, M., Cicchini, G. M., \& Burr, D. C. (2016). Adaptation to number operates on perceived rather than physical numerosity. Cognition, 151, 63-67. http://doi.org/10.1016/j.cognition.2016.03.006

Gallistel, C. R., \& Gelman, R. (2000). Non-verbal numerical cognition: From reals to integers. Trends in Cognitive Sciences, 4(2), 59-65. http://doi.org/10.1016/S1364-6613(99)01424-2

Galton, F. (1880). Visualised Numerals. Nature, 21(533), 252-256. http://doi.org/10.1038/021494e0

Ganor-Stern, D., Tzelgov, J., \& Ellenbogen, R. (2007). Automaticity and two-digit numbers. Journal of Experimental Psychology: Human Perception and Performance, 33(2), 483-496. http://doi.org/10.1037/0096-1523.33.2.483 
Gebuis, T., \& Reynvoet, B. (2012). The interplay between nonsymbolic number and its continuous visual properties. Journal of Experimental Psychology: General, 141(4), 642648. http://doi.org/10.1037/a0026218

Gelman, R., \& Gallistel, C. R. (1978). The Child's Understanding of Number. Harvard University Press.

Georges, C., Hoffmann, D., \& Schiltz, C. (in press). How and Why Do Number-Space Associations Co-Vary in Implicit and Explicit Magnitude Processing Tasks? Journal of Numerical Cognition.

Georges, C., Hoffmann, D., \& Schiltz, C. (2017). Mathematical abilities in elementary school: Do they relate to number-space associations? Journal of Experimental Child Psychology, 161, 126-147. http://doi.org/10.1016/j.jecp.2017.04.011

Gibson, L. C., \& Maurer, D. (2016). Development of SNARC and distance effects and their relation to mathematical and visuospatial abilities. Journal of Experimental Child Psychology, 150, 301-313. http://doi.org/10.1016/j.jecp.2016.05.009

Göbel, S. M. (2015). Up or down? Reading direction influences vertical counting direction in the horizontal plane - A cross-cultural comparison. Frontiers in Psychology, 6, 228. http://doi.org/10.3389/fpsyg.2015.00228

Göbel, S. M., Maier, C. A., \& Shaki, S. (2015). Which numbers do you have in mind? Number generation is influenced by reading direction. Cognitive Processing, 16, 241-244. http://doi.org/10.1007/s10339-015-0715-8

Göbel, S. M., Moeller, K., Pixner, S., Kaufmann, L., \& Nuerk, H. C. (2014). Language affects symbolic arithmetic in children: The case of number word inversion. Journal of Experimental Child Psychology, 119(1), 17-25. http://doi.org/10.1016/j.jecp.2013.10.001 
Gracia-Bafalluy, M., \& Noël, M. P. (2008). Does finger training increase young children's numerical performance? Cortex, 44(4), 368-375.

http://doi.org/10.1016/j.cortex.2007.08.020

Grant, E. (1972). Nicole Oresme and the medieval geometry of qualities and motions. A treatise on the uniformity and difformity of intensities known as "tractatus de configurationibus qualitatum et motuum": Marshall Clagett (ed. and tr.), edited with an introduction, Engli. Studies in History and Philosophy of Science Part A, 3(2), 167-182. http://doi.org/https://doi.org/10.1016/0039-3681(72)90022-2

Henik, A., \& Tzelgov, J. (1982). Is three greater than five: The relation between physical and semantic size in comparison tasks. Memory \& Cognition, 10(4), 389-395. http://doi.org/10.3758/BF03202431

Ho, \& Cheng. (1997). Training in Place-Value Concepts Improves Children's Addition Skills. Contemporary Educational Psychology, 22(4), 495-506.

Hoffmann, D., Hornung, C., Martin, R., \& Schiltz, C. (2013). Developing number-space associations: SNARC effects using a color discrimination task in 5-year-olds. Journal of Experimental Child Psychology, 116(4), 775-91. http://doi.org/10.1016/j.jecp.2013.07.013

Hoffmann, D., Mussolin, C., Martin, R., \& Schiltz, C. (2014). The impact of mathematical proficiency on the number-space association. PloS One, 9(1), e85048. http://doi.org/10.1371/journal.pone.0085048

Hoffmann, D., Pigat, D., \& Schiltz, C. (2014). The impact of inhibition capacities and age on number-space associations. Cognitive Processing, 15(3), 329-342. http://doi.org/10.1007/s10339-014-0601-9

Hohol, M., Cipora, K., Willmes, K., \& Nuerk, H. C. (2017). Bringing back the balance: Domain- 
general processes are also important in numerical cognition. Frontiers in Psychology, 8, 499. http://doi.org/10.3389/fpsyg.2017.00499

Huber, S., Klein, E., Moeller, K., \& Willmes, K. (2016). Spatial-numerical and ordinal positional associations coexist in parallel. Frontiers in Psychology, 7, 438. http://doi.org/10.3389/fpsyg.2016.00438

Huber, S., Moeller, K., \& Nuerk, H.-C. (2014). Dissociating number line estimations from underlying numerical representations. Quarterly Journal of Experimental Psychology, 67(5), 991-1003. http://doi.org/10.1080/17470218.2013.838974

Huber, S., Nuerk, H.-C., Willmes, K., \& Moeller, K. (2016). A general model framework for multisymbol number comparison. Psychological Review, 123(6), 667-695. http://doi.org/10.1037/rev0000040

Huber, S., Sury, D., Moeller, K., Rubinsten, O., \& Nuerk, H. C. (2015). A general number-tospace mapping deficit in developmental dyscalculia. Research in Developmental Disabilities, 43-44, 32-42. http://doi.org/10.1016/j.ridd.2015.06.003

Hyde, D. C., Khanum, S., \& Spelke, E. S. (2014). Brief non-symbolic, approximate number practice enhances subsequent exact symbolic arithmetic in children. Cognition, 131(1), 92107. http://doi.org/10.1038/jid.2014.371

Kallai, A. Y., \& Tzelgov, J. (2012). The place-value of a digit in multi-digit numbers is processed automatically. Journal of Experimental Psychology. Learning, Memory, and Cognition, 38(5), 1221-33. http://doi.org/10.1037/a0027635

Kim, D., \& Opfer, J. E. (2017). A unified framework for bounded and unbounded numerical estimation. Developmental Psychology, 53(6), 1088-1097. http://doi.org/10.1037/dev0000305 
Klein, E., Huber, S., Nuerk, H. C., \& Moeller, K. (2014). Operational momentum affects eye fixation behaviour. Quarterly Journal of Experimental Psychology, 67(8), 1614-1625. http://doi.org/10.1080/17470218.2014.902976

Knops, A., Viarouge, A., \& Dehaene, S. (2009). Dynamic representations underlying symbolic and nonsymbolic calculation: Evidence from the operational momentum effect. Attention, Perception \& Psychophysics, 71(4), 803-821. http://doi.org/10.3758/APP

Kucian, K., Grond, U., Rotzer, S., Henzi, B., Schönmann, C., Plangger, F., ... von Aster, M. (2011). Mental number line training in children with developmental dyscalculia. Neurolmage, 57(3), 782-795. http://doi.org/10.1016/j.neuroimage.2011.01.070

Landy, D., Charlesworth, A., \& Ottmar, E. (2014). Cutting in line: discontinuities in the use of large numbers in adults. In Proceedings of the 36th Annual Conference of the Cognitive Science Society (pp. 815-820).

Landy, D., Charlesworth, A., \& Ottmar, E. (2017). Categories of Large Numbers in Line Estimation. Cognitive Science, 41(2), 326-353. http://doi.org/10.1111/cogs.12342

Landy, D., \& Goldstone, R. L. (2010). Proximity and precedence in arithmetic. Quarterly Journal of Experimental Psychology, 63(10), 1953-1968. http://doi.org/10.1080/17470211003787619

Landy, D., Silbert, N., \& Goldin, A. (2013). Estimating large numbers. Cognitive Science, 37(5), 775-799. http://doi.org/10.1111/cogs.12028

Laski, E. V., \& Siegler, R. S. (2014). Learning from number board games: You learn what you encode. Developmental Psychology, 50(3), 853-864. http://doi.org/10.1037/a0034321

Laurillard, D. (2016). Learning number sense through digital games with intrinsic feedback. Australasian Journal of Educational Technology, 32(6), 32-44. 
http://doi.org/10.14742/ajet.3116

LeFevre, J. A., Lira, C. J., Sowinski, C., Cankaya, O., Kamawar, D., \& Skwarchuk, S. L. (2013). Charting the role of the number line in mathematical development. Frontiers in Psychology, 4, 641. http://doi.org/10.3389/fpsyg.2013.00641

Leibovich, T., \& Henik, A. (2013). Magnitude processing in non-symbolic stimuli. Frontiers in Psychology, 4, 375. http://doi.org/10.3389/fpsyg.2013.00375

Leibovich, T., Katzin, N., Harel, M., \& Henik, A. (2017). From "sense of number" to "sense of magnitude" - The role of continuous magnitudes in numerical cognition. Behavioral and Brain Sciences, 40, e164.

Lindemann, O., Alipour, A., \& Fischer, M. H. (2011). Finger Counting Habits in Middle Eastern and Western Individuals: An Online Survey. Journal of Cross-Cultural Psychology, 42(4), 566-578. http://doi.org/10.1177/0022022111406254

Lindskog, M., Winman, A., \& Poom, L. (2016). Arithmetic training does not improve approximate number system acuity. Frontiers in Psychology, 7, 1364. http://doi.org/10.3389/fpsyg.2016.01634

Link, T., Huber, S., Nuerk, H. C., \& Moeller, K. (2014). Unbounding the mental number line-new evidence on children's spatial representation of numbers. Frontiers in Psychology, 4, 1021. http://doi.org/10.3389/fpsyg.2013.01021

Link, T., Moeller, K., Huber, S., Fischer, U., \& Nuerk, H.-C. (2013). Walk the number line - An embodied training of numerical concepts. Trends in Neuroscience and Education, 2(2), 7484. http://doi.org/10.1016/j.tine.2013.06.005

Link, T., Nuerk, H.-C., \& Moeller, K. (2014). On the relation between the mental number line and arithmetic competencies. Quarterly Journal of Experimental Psychology, 67(8), 1597-1613. 
http://doi.org/10.1080/17470218.2014.892517

Loetscher, T., Schwarz, U., Schubiger, M., \& Brugger, P. (2008). Head turns bias the brain's internal random generator. Current Biology : $C B, 18(2), \mathrm{R} 60-2$. http://doi.org/10.1016/j.cub.2007.11.015

Lonnemann, J., Krinzinger, H., Knops, A., \& Willmes, K. (2008). Spatial representations of numbers in children and their connection with calculation abilities. Cortex, 44(4), 420-428. http://doi.org/10.1016/j.cortex.2007.08.015

Lyons, I. M., Nuerk, H.-C., \& Ansari, D. (2015). Rethinking the implications of numerical ratio effects for understanding the development of representational precision and numerical processing across formats. Journal of Experimental Psychology: General, 144(5), 102135. http://doi.org/10.1037/xge0000094

Maertens, B., De Smedt, B., Sasanguie, D., Elen, J., \& Reynvoet, B. (2016). Enhancing arithmetic in pre-schoolers with comparison or number line estimation training: Does it matter? Learning and Instruction, 46, 1-11.

http://doi.org/10.1016/j.learninstruc.2016.08.004

Masson, N., \& Pesenti, M. (2014). Attentional bias induced by solving simple and complex addition and subtraction problems. Quarterly Journal of Experimental Psychology, 67(8), 1514-1526. http://doi.org/10.1080/17470218.2014.903985

Masson, N., Letesson, C., \& Pesenti, M. (in press). Time course of attentional shifts in mental arithmetic: evidence from gaze metrics. Quarterly Journal of Experimental Psychology. https://doi.org/10.1080/17470218.2017.1318931

McCrink, K., Dehaene, S., \& Dehaene-Lambertz, G. (2007). Moving along the number line: Operational momentum in nonsymbolic arithmetic. Perception \& Psychophysics, 69(8), 
1324-1333. http://doi.org/10.3758/BF03192949

Miura, I. T., Okamoto, Y., Kim, C. C., Chang, C.-M., Steere, M., \& Fayol, M. (1994).

Comparisons of Children's Cognitive Representation of Number: China, France, Japan, Korea, Sweden, and the United States. International Journal of Behavioral Development, 17(3), 401-411. http://doi.org/10.1177/016502549401700301

Mix, K., Levine, S., Cheng, Y.-L., Young, C., Hambrick, D., Ping, R., \& Konstantopoulos, S. (2016). Separate But Correlated: The Latent Structure of Space and Mathematics Across Development. Journal of Experimental Psychology: General, 145(9), 1206-1227. http://doi.org/10.1037/xge0000182

Moeller, K., Pixner, S., Kaufmann, L., \& Nuerk, H.-C. (2009). Children's early mental number line: logarithmic or decomposed linear? Journal of Experimental Child Psychology, 103(4), 503-15. http://doi.org/10.1016/j.jecp.2009.02.006

Moeller, K., Pixner, S., Zuber, J., Kaufmann, L., \& Nuerk, H. C. (2011). Early place-value understanding as a precursor for later arithmetic performance-A longitudinal study on numerical development. Research in Developmental Disabilities, 32(5), 1837-1851. http://doi.org/10.1016/j.ridd.2011.03.012

Moeller, K., Shaki, S., Göbel, S. M., \& Nuerk, H.-C. (2015). Language influences number processing - A quadrilingual study. Cognition, 136, 150-155.

http://doi.org/10.1016/j.cognition.2014.11.003

Moyer, R. S., \& Landauer, T. K. (1967). Time required for Judgements of Numerical Inequality. Nature, 215(5109), 1519-1520. http://doi.org/10.1038/2151519a0

Nemati, P., Schmid, J., Soltanlou, M., Krimly, J.-T., Nuerk, H.-C., \& Gawrilow, C. (in press). Planning and self-control, but not working memory, directly predict multiplication 
performance in adults. Journal of Numerical Cognition.

Nuerk, H.-C., Moeller, K., Klein, E., Willmes, K., \& Fischer, M. H. (2011). Extending the mental number line: A review of multi-digit number processing. Zeitschrift Für Psychologie/Journal of Psychology, 219(1), 3-22.

Nuerk, H.-C., Moeller, K., \& Willmes, K. (2015). Multi-Digit Number Processing: overview, conceptual clarifications, and language influences. In R. Cohen Kadosh \& A. Dowker (Eds.), The Oxford Handbook of Numerical Cognition. http://doi.org/10.1027/2151$2604 / a 000040$

Nuerk, H.-C., Weger, U., \& Willmes, K. (2001). Decade breaks in the mental number line? Putting the tens and units back in different bins. Cognition, 82(1). http://doi.org/10.1016/S0010-0277(01)00142-1

Obersteiner, A., Reiss, K., \& Ufer, S. (2013). How training on exact or approximate mental representations of number can enhance first-grade students' basic number processing and arithmetic skills. Learning and Instruction, 23(1), 125-135.

http://doi.org/10.1016/j.learninstruc.2012.08.004

Opfer, J. E., \& Siegler, R. S. (2007). Representational change and children's numerical estimation. Cognitive Psychology, 55(3), 169-195.

http://doi.org/10.1016/j.cogpsych.2006.09.002

Park, J., \& Brannon, E. M. (2013). Training the approximate number system improves math proficiency. Psychological Science, 24(10), 2013-9.

http://doi.org/10.1177/0956797613482944

Patro, K., Fischer, U., Nuerk, H.-C., \& Cress, U. (2016). How to rapidly construct a spatialnumerical representation in preliterate children (at least temporarily). Developmental 
Science, 19(1), 126-144. http://doi.org/10.1111/desc.12296

Patro, K., Nuerk, H.-C., Cress, U., \& Haman, M. (2014). How number-space relationships are assessed before formal schooling: A taxonomy proposal. Frontiers in Psychology, 5, 419. http://doi.org/10.3389/fpsyg.2014.00419

Penner-Wilger, M., \& Anderson, M. L. (2013). The relation between finger gnosis and mathematical ability: Why redeployment of neural circuits best explains the finding. Frontiers in Psychology, 4, 877. http://doi.org/10.3389/fpsyg.2013.00877

Pesenti, M. (2005). Calculation abilities in expert calculators. In Handbook of mathematical cognition (pp. 413-430). Psychology Press New York, NY.

Pfister, R., Schroeder, P. A., \& Kunde, W. (2013). SNARC struggles: Instant control over spatial-numerical associations. Journal of Experimental Psychology: Learning, Memory, and Cognition, 39(6), 1953-8. http://doi.org/10.1037/a0032991

Piazza, M., \& Izard, V. (2009). How Humans Count: Numerosity and the Parietal Cortex. The Neuroscientist, 15(3), 261-273. http://doi.org/10.1177/1073858409333073

Piazza, M., Mechelli, A., Butterworth, B., \& Price, C. J. (2002). Are Subitizing and Counting Implemented as Separate or Functionally Overlapping Processes? Neurolmage, 15(2), 435-446. http://doi.org/10.1006/nimg.2001.0980

Pinhas, M., Shaki, S., \& Fischer, M. H. (2014). Heed the signs: Operation signs have spatial associations. Quarterly Journal of Experimental Psychology, 67(8), 1527-1540. http://doi.org/10.1080/17470218.2014.892516

Pinheiro-Chagas, P., Dotan, D., Piazza, M., \& Dehaene, S. (2017). Finger Tracking Reveals the Covert Stages of Mental Arithmetic Pedro. Open Mind, 1(1), 30-41. http://doi.org/10.1162/opmi 
Ramani, G. B., Siegler, R. S., \& Hitti, A. (2012). Taking it to the classroom: Number board games as a small group learning activity. Journal of Educational Psychology, 104(3), 661672. http://doi.org/10.1037/a0028995

Raz, A., \& Buhle, J. (2006). Typologies of attentional networks. Nature Reviews Neuroscience, 7(5), 367-379. http://doi.org/10.1038/nrn1903

Restle, F. (1970). Speed of adding and comparing numbers. Journal of Experimental Psychology, 83(2, Pt. 1), 274-278.

Rodic, M., Zhou, X., Tikhomirova, T., Wei, W., Malykh, S., Ismatulina, V., ... Kovas, Y. (2015). Cross-cultural investigation into cognitive underpinnings of individual differences in early arithmetic. Developmental Science, 18(1), 165-174. http://doi.org/10.1111/desc.12204

Rubinsten, O., \& Sury, D. (2011). Processing Ordinality and Quantity: The Case of Developmental Dyscalculia. Plos One, 6(9), e24079. http://doi.org/10.1371/journal.pone.0024079

Sasanguie, D., \& Reynvoet, B. (2014). Adults' arithmetic builds on fast and automatic processing of Arabic digits: Evidence from an audiovisual matching paradigm. PLoS ONE, 9(2). http://doi.org/10.1371/journal.pone.0087739

Schneider, M., Beeres, K., Coban, L., Merz, S., Susan Schmidt, S., Stricker, J., \& De Smedt, B. (2017). Associations of non-symbolic and symbolic numerical magnitude processing with mathematical competence: a meta-analysis. Developmental Science, 20(3). http://doi.org/10.1111/desc.12372

Schneider, M., Grabner, R. H., Zurich, E., \& Paetsch, J. (2009). Mental Number Line, Number Line Estimation, and Mathematical Achievement: Their Interrelations in Grades 5 and 6. Journal of Educational Psychology, 101(2), 359-372. http://doi.org/10.1037/a0013840 
Schroeder, P. A., Nuerk, H.-C., \& Plewnia, C. (in press). Space in Numerical and Ordinal Information: A Common Construct? Journal of Numerical Cognition.

Schroeder, P. A., Nuerk, H.-C., \& Plewnia, C. (2017). Switching between Multiple Codes of SNARC-Like Associations: Two Conceptual Replication Attempts with Anodal tDCS in Sham-Controlled Cross-Over Design. Frontiers in Neuroscience, 11, 654. http://doi.org/10.3389/fnins.2017.00654

Schroeder, P. A., \& Pfister, R. (2015). Arbitrary numbers counter fair decisions: trails of markedness in card distribution. Frontiers in Psychology, 6, 240. http://doi.org/10.3389/fpsyg.2015.00240

Sella, F., Tressoldi, P., Lucangeli, D., \& Zorzi, M. (2016). Training numerical skills with the adaptive videogame "The Number Race": A randomized controlled trial on preschoolers. Trends in Neuroscience and Education, 5(1), 20-29. http://doi.org/10.1016/j.tine.2016.02.002

Shaki, S., \& Fischer, M. H. (2014). Random walks on the mental number line. Experimental Brain Research, 232(1), 43-9. http://doi.org/10.1007/s00221-013-3718-7

Shaki, S., Fischer, M. H., \& Göbel, S. M. (2012). Direction counts: A comparative study of spatially directional counting biases in cultures with different reading directions. Journal of Experimental Child Psychology, 112(2), 275-281. http://doi.org/10.1016/j.jecp.2011.12.005

Shaki, S., Fischer, M. H., \& Petrusic, W. M. (2009). Reading habits for both words and numbers contribute to the SNARC effect. Psychonomic Bulletin \& Review, 16(2), 328-31. http://doi.org/10.3758/PBR.16.2.328

Shaki, S., \& Gevers, W. (2011). Cultural characteristics dissociate magnitude and ordinal information processing. Journal of Cross-Cultural Psychology, 42(4), 639-650. 
http://doi.org/10.1177/0022022111406100

Siegler, R. S., \& Booth, J. L. (2004). Development of numerical estimation in young children. Child Development, 75(2), 428-444. http://doi.org/10.1111/j.1467-8624.2004.00684.x

Siegler, R. S., \& Opfer, J. E. (2003). The development of numerical estimation: evidence for multiple representations of numerical quantity. Psychological Science, 14(3), 237-243.

Siegler, R. S., \& Ramani, G. B. (2009). Playing linear number board games—but not circular ones-improves low-income preschoolers' numerical understanding. Journal of Educational Psychology, 101(3), 545-560. http://doi.org/10.1037/a0014239

Siegler, R. S., Thompson, C. A., \& Opfer, J. E. (2009). The logarithmic-to-linear shift: One learning sequence, many tasks, many time scales. Mind, Brain, and Education, 3(3), 143150. http://doi.org/10.1111/j.1751-228X.2009.01064.x

Simner, J., Mayo, N., \& Spiller, M. J. (2009). A foundation for savantism? Visuo-spatial synaesthetes present with cognitive benefits. Cortex, 45(10), 1246-1260. http://doi.org/10.1016/j.cortex.2009.07.007

Stavy, R., \& Tirosh, D. (2000). How students (mis-) understand science and mathematics: Intuitive rules. Teachers College Press.

Szücs, D., Nobes, A., Devine, A., Gabriel, F. C., \& Gebuis, T. (2013). Visual stimulus parameters seriously compromise the measurement of approximate number system acuity and comparative effects between adults and children. Frontiers in Psychology, 4, 444. http://doi.org/10.3389/fpsyg.2013.00444

Tudusciuc, O., \& Nieder, A. (2007). Neuronal population coding of continuous and discrete quantity in the primate posterior parietal cortex. PNAS, 104(36), 14513-14518. http://doi.org/0705495104 [pii]ır10.1073/pnas.0705495104 
van Dijck, J.-P., \& Fias, W. (2011). A working memory account for spatial-numerical associations. Cognition, 119(1), 114-9. http://doi.org/10.1016/j.cognition.2010.12.013

Verbruggen, F., Liefooghe, B., Notebaert, W., \& Vandierendonck, A. (2005). Effects of stimulusstimulus compatibility and stimulus-response compatibility on response inhibition. Acta Psychologica, 120(3), 307-326. http://doi.org/10.1016/j.actpsy.2005.05.003

Viarouge, A., Hubbard, E. M., \& Dehaene, S. (2014). The organization of spatial reference frames involved in the SNARC effect. Quarterly Journal of Experimental Psychology, 67(8), 1484-99. http://doi.org/10.1080/17470218.2014.897358

Viarouge, A., Hubbard, E. M., \& McCandliss, B. D. (2014). The cognitive mechanisms of the SNARC effect: An individual differences approach. PLoS ONE, 9(4). http://doi.org/10.1371/journal.pone.0095756

Wasner, M., Moeller, K., Fischer, M. H., \& Nuerk, H.-C. (2014). Aspects of situated cognition in embodied numerosity: the case of finger counting. Cognitive Processing, 15(3), 317-28. http://doi.org/10.1007/s10339-014-0599-z

Wiemers, M., Bekkering, H., \& Lindemann, O. (2014). Spatial interferences in mental arithmetic: Evidence from the motion-arithmetic compatibility effect. Quarterly Journal of Experimental Psychology, 67(8), 1557-1570. http://doi.org/10.1080/17470218.2014.889180

Wiemers, M., Bekkering, H., \& Lindemann, O. (2017). Is More Always Up? Evidence for a Preference of Hand-Based Associations over Vertical Number Mappings. Journal of Cognitive Psychology, 29(5), 642-652. http://doi.org/10.1080/20445911.2017.1302451

Wilson, A. J., Dehaene, S., Pinel, P., Revkin, S. K., Cohen, L., \& Cohen, D. (2006). Principles underlying the design of "The Number Race", an adaptive computer game for remediation of dyscalculia. Behavioral and Brain Functions, 2, 19. http://doi.org/10.1186/1744-9081-2- 
Wilson, M. (2002). Six views of embodied cognition. Psychonomic Bulletin \& Review, 9(4), 625636. http://doi.org/10.3758/BF03196322

Wood, G., Willmes, K., Nuerk, H.-C., \& Fischer, R. (2008). On the cognitive link between space and number: A meta-analysis of the SNARC effect. Psychology Science Quarterly, 50(4), $489-525$.

Zohar-Shai, B., Tzelgov, J., Karni, A., \& Rubinsten, O. (2017). It does exist! A left-to-right spatial-numerical association of response codes (SNARC) effect among native Hebrew speakers.. Journal of Experimental Psychology: Human Perception and Performance, 43(4), 719-728. http://doi.org/10.1037/xhp0000336

Zuber, J., Pixner, S., Moeller, K., \& Nuerk, H. C. (2009). On the language specificity of basic number processing: Transcoding in a language with inversion and its relation to working memory capacity. Journal of Experimental Child Psychology, 102(1), 60-77. http://doi.org/10.1016/j.jecp.2008.04.003 


\section{$\underline{B O X} 1$}

\section{A. Key terms and concepts of experimental psychology used in this chapter}

Attention (see Raz \& Buhle, 2006). Attention is a mechanism of information selection. One of the most influential models of attention outlined by Posner (see: Petersen \& Poster, 2012) postulates three independent networks: alerting, orienting, and executive. The alerting system controls the arousal level and sustained vigilance. The orienting system prioritizes sensory input from a particular sensory modality and / or location in space. Executive attention is responsible for inhibition of irrelevant responses, conflict monitoring, and switching between tasks. In this chapter, two components of attention are of particular importance. Orienting (related to spatial shifts of attentional focus) and executive, especially components related to inhibition and conflict monitoring, will be discussed in the context of the role the domain-general factors play in SNAs.

Compatibility effect (see Kornblum et al., 1990). This term describes the fact that some tasks are easier or more difficult depending on stimuli and response sets used. For instance, it is easier to respond if a meaning of the stimulus (e.g., left/right pointing arrow) corresponds to the required response (e.g., left/right located key) than when it does not (stimulus-response compatibility). Task difficulty also differs depending on the meaning of objects being presented (stimulus-stimulus compatibility; e.g., Verbruggen et al., 2005). Namely, the task is easier if irrelevant stimuli presented together with the target stimulus are associated with the same response, than when they are associated with another response. Differences in task difficulty are reflected in reaction times, reaction time variances, error rates (all larger for incompatible trials), as well as in neural correlates of cognitive processing (differences in electrical or metabolic brain responses). This is because in case of incompatible trials, competing cognitive processes involved in initiating different responses need to be resolved by cognitive control. Compatibility effects are widely used in the domain of numerical cognition in investigating Spatial Numerical Associations (SNAs) or the multi-digit number processing. 
Domain-specific and domain-general processes (see Hohol et al., 2017). Domain-general processes can be viewed as mental general-purpose tools, which can be used to process a very broad range of information (e.g., numerical, spatial, verbal, and so on). On the contrary, domainspecific processes are those specialized in processing particular type of information (e.g., quantity). One of the most important debates in numerical cognition is the interplay and mutual relationships between these two types of processes and the roles they play.

\section{B. Key terms and phenomena investigated within numerical cognition}

Estimation (see Gallistel \& Gelman, 2000). The ability to provide an approximate number of elements in a collection, possessed by humans and several other species. The cognitive system responsible for this process is called the Approximate Number System (ANS). The accuracy of estimation decreases with an increasing number of elements; however, the minimal ratio enabling successful discrimination between sets is constant within an individual (the Weber fraction; see Piazza \& Izard, 2009). In other words, the larger is the absolute size of the set, the greater the absolute difference between sets must be (so that this ratio remains constant) in order to enable successful discrimination.

Mental Number Line (MNL; Restle, 1970). A theoretical construct or a metaphor on how numbers are mentally represented. According to this view, numbers are represented as the points on a directional number line. It is claimed that the MNL is logarithmically compressed (i.e., distances between small numbers are larger than distances between large numbers).

Numerical distance effect (Moyer \& Landauer, 1967). This term denotes the observation that the time required to perform number comparisons increases with a decreasing difference between the numbers to be compared. It can be observed for both non-symbolic (dot patterns) and symbolic (e.g. Arabic numbers) notation. The numerical distance effect can be split into absolute (e.g., in 85_53, is $85-53=32$ ), decade (e.g., in 85_53, is $8-5=3$ ), and unit distance 
(e.g., in 85_53, is 5 - $3=2$ ) aspects. Importantly, similar effects in the context of comparing physical objects (e.g., line length) were described earlier in classical Gestalt psychology literature (see Cohen Kadosh et al., 2008).

Ratio effect (see Lyons et al., 2015). This term denotes the relationship between numerical ratio (i.e., the ratio of numbers to be compared) and comparison task performance: the performance decreases as the ratio approaches " 1 ". The ratio effect is very similar to the distance effect; however, it considers the absolute magnitude of numbers to be compared. Thus, to some extent the ratio effect takes into account both distance and size effects.

Size effect (see Brysbaert, 1995). It denotes the observation that the time needed to make numerical judgments increases with increasing magnitude. As in the case of the numerical distance effect, the size effect was first observed in tasks requiring comparison of physical properties of objects.

\section{Spatial-Numerical Association of Response Codes (SNARC; Dehaene et al., 1993).}

SNARC denotes an observation that numerical magnitudes are associated with space: in left-toright readers, small magnitude numbers are associated with the left hand side, whereas large magnitude numbers are associated with the right hand side.

Spatial-Numerical Associations (SNA; see Cipora et al., 2015). A broad range of phenomena demonstrating that numbers (especially their magnitudes) are bidirectionally associated with space. Can be observed by means of behavioral or neural signatures.

Subitizing (see Piazza et al., 2002). From the Latin word subitius (sudden). An elementary capacity to quickly and effortlessly determine the number of elements in small sets (i.e., no larger than 4 elements) possessed by humans and other species.

Unit-decade compatibility effect (Nuerk et al., 2001. Denotes the fact that while comparing two two-digit numbers, responses are faster and more accurate if the number of units in the 60 
numerically larger number is larger than the number of units in the numerically smaller number (compatible trial, e.g., 23_69), than in a situation when the number of units in the larger number is smaller than in the smaller number (incompatible trial, e.g., 29_63).

Place-value processing (Nuerk et al., 2015). The place-value concept refers to the value of a digit according to its position within a sequence of digits in the Arabic number system. The value of a digit increases by a power of 10 (base-10 system) with each step going from the right digit to the left digit in a multi-digit Arabic number (e.g., $257=[2] \times 10^{2}+[5] \times 10^{1}+[7] \times 10^{0}$ ). Nuerk et al. (2015) proposed a three-level categorization of componential processing for place-value understanding: place identification, place-value activation, and place-value computation.

\section{BOX 2 - Measuring Spatial-Numerical Associations}

Several tasks have been developed in order to tap how humans associate numbers with space. They will be briefly discussed below. This overview shows that numbers seem to be inherently associated with space, irrespective of the type of task used to measure it.

\section{Extension SNA - Approximate:}

Interference tasks measuring the size congruity effect (Henik \& Tzelgov, 1982). The participants are presented with pairs of numbers differing both in physical size and numerical magnitude. The participant's task is to indicate either the physically or numerically larger one. Difference in reaction times between congruent (physically larger number is also numerically larger) and incongruent (physically larger number is numerically smaller) trials are measured.

Following cardinality across modalities (de Hevia \& Spelke, 2010). Used in infant studies. Children are familiarized with either ascending or descending sequences of one type of stimuli (e.g., a line becoming longer and longer). Subsequently, the test probe (either an ascending or descending sequence of another type of stimuli e.g., an increasing number of dots) is 
presented. Looking times are compared between trials in which the order in the test probe was familiar or novel.

Line bisection task (Fischer, 2001). Participant's task is to indicate the midpoint of the line. The line is either constructed out of numbers (e.g. 99999999999999; M. H. Fischer, 2001) or flanked with numbers presented either in symbolic or nonsymbolic format (e.g., 2-----------7; de Hevia \& Spelke, 2009). In the first case midpoint is biased to the left/right when line is built of small/large magnitude numbers. In the second case, the midpoint is located closer to the larger magnitude number.

Spatial arrangement of operation order (Landy \& Goldstone, 2010). Participants are presented with arithmetic operations in which following the operation order is essential. The physical spacing between numbers can be either congruent (e.g., $\left.2^{\star} 2+2\right)$ or incongruent (e.g., 2 * 2+2) with the operation order. Reaction times are compared between conditions.

\section{Extension SNA - Exact}

Number line estimation (Siegler \& Opfer, 2003). There are two major variations of this task, namely bounded and unbounded versions (Cohen \& Blanc-Goldhammer, 2011). In the bounded number line estimation the participant is presented with a line marked with numbers on both of its ends (e.g., 0 and 100). In the unbounded task, only the left side of the number is marked with a number. Additionally there is another short line indicating one unit. In both cases the task is to mark the position of a given number on the line. Recently another variation of the task was developed in which touchscreen technology is used not only to track the response given by the participant but also the exact movement trajectory.

Directional SNA - implicit coding - cardinality

Parity judgment task (e.g. Dehaene et al., 1993). The participant is to make binary decisions on whether the presented number is odd or even. Two lateralized response keys are used. In 
the mid-experiment, the response-to-key assignment is switched so that both right- and lefthand responses are collected for each number.

Magnitude classification task (see Wood et al., 2008). The participant is to make binary decisions on whether the presented number is smaller or larger than a criterion value (which is constant across the experiment). Two lateralized response keys are used. Similarly to parity judgment, response-to-key assignment is flipped in the mid-experiment.

Magnitude comparison task (see Wood et al., 2008). The criterion value according to which the numerical value of the target number is compared changes from trial to trial.

Other binary decisions on numerical magnitude (e.g. Fias et al., 2001). The participants are deciding on other characteristics of the number (e.g., whether it contains a particular phoneme or whether it is written upright or with italics).

Directional SNA - implicit coding - place-value

Physical comparison task (Ganor-Stern et al., 2007): A variation of a typical two-digit number comparison task. While one number is shown in large font, the other is shown in small font, irrelevant to the magnitude of the numbers. In half of the trials the magnitude and physical size of the number pairs are compatible but not in the other half. Participants are to decide which number is physically larger, while ignoring numerical magnitudes.

Directional SNA - implicit coding - ordinality

Parity judgment task with working memory load. This is a variation of the typical parity judgment task in which the participant is first asked to memorize a sequence of numbers and then performs the typical parity task. The participant is to react only to numbers, which were present in the sequence. After a block of such trials, it is checked whether the participant can correctly recall the sequence. 
Directional SNA - implicit coding - functions

Spatial biases in mental arithmetic (Knops et al., 2009). Participants are to perform operations (additions and subtractions) on either symbolic or nonsymbolic material. It is tested whether performing such operations influences concurrent spatial activity (directional hand movements, oculomotor activity, lateral attentional shifts).

Arithmetic sign and space (Pinhas et al., 2014). The participants decide whether the presented sign is "+" or "-" using two response keys.

Directional SNA - explicit coding - place value

Two-digit number comparison (Nuerk, et al., 2001): Two two-digit numbers are presented simultaneously on the screen with the same font size, while they differ in magnitude.

Participants are asked to select the numerically larger number.

Directional SNA - explicit coding - ordinality

Counting tasks (e.g. Shaki et al., 2012). Such tasks are used mostly in cross cultural children's studies. Participants are presented with a row or a matrix of tokens and are asked to count them. The direction of counting is checked.

The tasks may involve several response formats. Binary decisions can be made bimanually, unimanually using two different fingers or with a single finger in a pointing task. Responses may also be given using feet or directional eye movements. In other setups responses may be given orally, by pointing, grasping, or the whole movement trajectory can be measured (Fischer \& Shaki, 2014 for review). 


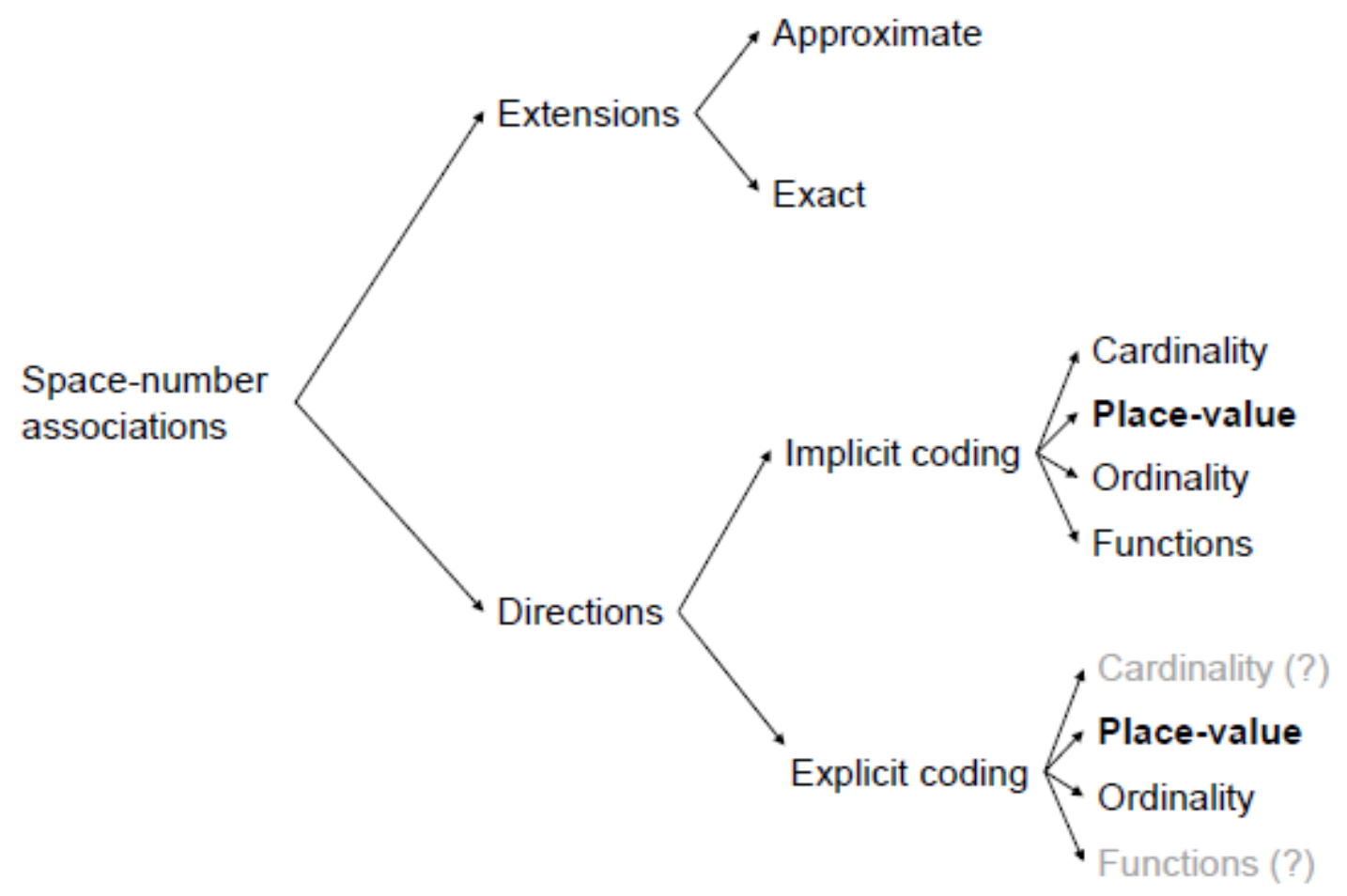

Fig 1. Overview of the Spatial-Numerical Associations (SNAs) taxonomy. 